OPEN ACCESS

Edited by:

Mahmoud Iravani, University of Hertfordshire, United Kingdom

Reviewed by:

Grzegorz Kreiner, Polish Academy of Sciences, Poland

Anna Maria Pittaluga, University of Genoa, Italy

${ }^{*}$ Correspondence:

Cristina Miguelez cristina.miguelez@ehu.eus

Specialty section: This article was submitted to

Neuropharmacology, a section of the journal Frontiers in Pharmacology

Received: 08 October 2019 Accepted: 20 March 2020

Published: 08 April 2020

Citation:

Paredes-Rodriguez E, VegasSuarez S, Morera-Herreras T, De Deurwaerdere $P$ and Miguelez $C$ (2020) The Noradrenergic System in

Parkinson's Disease.

Front. Pharmacol. 11:435. doi: 10.3389/fphar.2020.00435

\section{The Noradrenergic System in Parkinson's Disease}

\author{
Elena Paredes-Rodriguez ${ }^{1,2}$, Sergio Vegas-Suarez ${ }^{1,2}$, Teresa Morera-Herreras $^{1,2}$, \\ Philippe De Deurwaerdere ${ }^{3}$ and Cristina Miguelez ${ }^{1,2 *}$ \\ 1 Department of Pharmacology, Faculty of Medicine and Nursing, University of the Basque Country (UPV/EHU), Leioa, Spain, \\ ${ }^{2}$ Autonomic and Movement Disorders Unit, Neurodegenerative Diseases, Biocruces Health Research Institute, Barakaldo, \\ Spain, ${ }^{3}$ Centre National de la Recherche scientifique, Institut des Neurosciences Cognitives et Intégratives d'Aquitaine (INCIA \\ UMR 5287), Bordeaux, France
}

Nowadays it is well accepted that in Parkinson's disease (PD), the neurodegenerative process occurs in stages and that damage to other areas precedes the neuronal loss in the substantia nigra pars compacta, which is considered a pathophysiological hallmark of PD. This heterogeneous and progressive neurodegeneration may explain the diverse symptomatology of the disease, including motor and non-motor alterations. In PD, one of the first areas undergoing degeneration is the locus coeruleus (LC). This noradrenergic nucleus provides extensive innervation throughout the brain and plays a fundamental neuromodulator role, participating in stress responses, emotional memory, and control of motor, sensory, and autonomic functions. Early in the disease, LC neurons suffer modifications that can condition the effectiveness of pharmacological treatments, and importantly, can lead to the appearance of common non-motor symptomatology. The noradrenergic system also exerts anti-inflammatory and neuroprotective effect on the dopaminergic degeneration and noradrenergic damage can consequently condition the progress of the disease. From the pharmacological point of view, it is also important to understand how the noradrenergic system performs in PD, since noradrenergic medication is often used in these patients, and drug interactions can take place when combining them with the gold standard drug therapy in $\mathrm{PD}, \mathrm{L}-3,4$-dihydroxyphenylalanine (L-DOPA). This review provides an overview about the functional status of the noradrenergic system in PD and its contribution to the efficacy of pharmacologicalbased treatments. Based on preclinical and clinical publications, a special attention will be dedicated to the most prevalent non-motor symptoms of the disease.

Keywords: Parkinson's disease, noradrenaline, locus coeruleus, non-motor symptoms, neuroprotection, prodromic, L-DOPA, neuroinflammation

\section{INTRODUCTION}

Parkinson's disease (PD) is a progressive neurodegenerative disorder characterized by the presence of $\alpha$-synuclein protein aggregates in the form of Lewy bodies in specific brain regions. These aggregates may be responsible for the onset and progression of the disease likely by promoting mitochondrial dysfunction, microglial activation, and neuroinflammatory responses, but they do 
not appear all over the brain at the same time. Indeed, recent publications have suggested that the $\alpha$-synuclein pathology begins in the gut and travels via the vagal nerve up to the brain where it spreads following the six stages defined by Braak and colleagues (Ulusoy et al., 2013; Kim et al., 2019). Although historically the hallmark of the disease has been focused on the degeneration of the substantia nigra pars compacta (SNc), it is now well accepted that the spread of $\alpha$-synuclein in the brain occurs in stages and that damage to other areas precedes the degeneration of SNc neurons, affecting glutamatergic, noradrenergic, serotonergic, histaminergic, and cholinergic projection cells (Del Tredici et al., 2002; Braak et al., 2003). This heterogeneous, progressive neurodegeneration may explain the diverse symptomatology of $\mathrm{PD}$, which includes motor and non-motor alterations (Chaudhuri and Schapira, 2009). Indeed, $\mathrm{PD}$ is more likely to be a multisystem disorder rather than a pure motor disease.

According to Braak's theory (Brak et al., 2004), the first $\alpha$ synuclein aggregates in the central nervous system appear in the anterior olfactory structures and the dorsal motor nucleus of the vagus nerve, following by lower raphe system and the locus coeruleus (LC) in stage 2. It is not until stage 3 that the $\mathrm{SNc}$ is affected together with the amygdala, tegmental pedunculopontine nucleus, and the higher raphe nuclei, among others. During stage 4, $\alpha$-synuclein spreads to the hippocampal formation and specific cortical areas and finally, in the last two stages (5 and 6), almost the whole cortex is damaged. This pattern of $\alpha$-synuclein propagation between interconnected nuclei has also been mimicked in animal models in which $\alpha$-synuclein was overexpressed by means of viral vector administration in peripheral structures (Rey et al., 2013; Ulusoy et al., 2013; Ulusoy et al., 2017; Rusconi et al., 2018). The pathological process underlying PD would consist of a prodromal period followed by a symptomatic one when the disease is often diagnosed. The presymptomatic or prodromal phase (stages 1-3) is often characterized by olfactory dysfunction, autonomic dysregulation, pain, sleep, and mood disorders while the symptomatic phase (stages $4-6$ ) is accompanied by the classical somatomotor symptoms and impaired cognitive functioning (Chaudhuri and Schapira, 2009; Braak and Del Tredici, 2016).

Among the brain areas that undergo degeneration in the prodromal phase, the LC deserves special attention for being one of the first nuclei to develop Lewy bodies, and because LC dysfunction may be related to several of the non-motor symptoms observed in the disease. Here, we will review the functional status of the LC in PD using data from experimental models and patients. We will also analyze the potential role of the LC in PD-associated neuroinflammation, the appearance of nonmotor complications, and the pharmacological therapies.

\section{THE LOCUS COERULEUS}

The LC is a bilateral nucleus located in the upper dorsolateral pontine tegmentum and is considered the principal noradrenergic nucleus in the central nervous system (Amaral and Sinnamon, 1977). Although noradrenergic neurons are the biggest cell population, GABAergic interneurons also inhabit the LC making synapses and efficiently inhibit the noradrenergic neurons (Aston-Jones et al., 2004; Jin et al., 2016; BretonProvencher and Sur, 2019). Neurochemical content and receptor expression are also very heterogeneous containing adrenergic, GABAergic, serotonergic, glutamatergic, $\mu$-opioid, orexin/hypocreatin, nicotinic acetylcholine, and cannabinoid receptors (reviewed in Berridge and Waterhouse, 2003; Schwarz and Luo, 2015). LC noradrenergic cells, as happens with SNc neurons, also contains neuromelanin which makes them specially vulnerable to neurodegeneration in PD (reviewed in Martin-Bastida et al., 2017 and Vila, 2019).

Despite being a tiny nucleus, the LC shows an enormous projecting network, influencing the activity of nuclei all over the brain. It sends descending projections to the spinal cord (Westlund et al., 1983) and densely innervates ascending areas of the CNS as the amygdala, superior colliculus, paraventricular thalamic nucleus, hippocampus, olfactory bulb, dorsal raphe, and cortex, including prefrontal, orbitofrontal, anterior cingulate, and primary motor cortices (Fallon et al., 1978; Shipley et al., 1985; Loughlin et al., 1986; Kim et al., 2004; Chandler et al., 2014; Schwarz et al., 2015; Kempadoo et al., 2016; Takeuchi et al., 2016; McCall et al., 2017; Beas et al., 2018; Li L. et al., 2018). The SNc and the ventral tegmental area also receive modest noradrenergic innervation from the LC (Baldo et al., 2003; Mejías-Aponte et al., 2009). By contrast, those areas with intense dopaminergic innervation as the nucleus accumbens or the striatum show discrete noradrenergic innervation (Mason and Fibiger, 1979; Berridge et al., 1997; Delfs et al., 1998; Fitoussi et al., 2013). As for the afferences, the LC also receives a large variety of inputs including those from the paragigantocellularis, prepositus hypoglossi, dorsal raphe, superior colliculus, prefrontal cortex, or the SNc (Aston-Jones et al., 1986; Devoto et al., 2005b; Delaville et al., 2011; Lu et al., 2012; Breton-Provencher and Sur, 2019).

It is interesting to mention that although the LC does not project to nuclei highly innervated by the dopaminergic system, it can still influence dopaminergic transmission distally. Devoto and collaborators have extensively characterized that LCtyrosine hydroxylase positive fibers can co-release not only noradrenaline (NA) but also dopamine (DA) in the cortex, including prefrontal, parietal, and occipital cortices involving $\alpha_{2}$-adrenoceptor-mediated mechanisms (Devoto et al., 2001; Devoto et al., 2003; Devoto et al., 2004; Devoto et al., 2005a; Devoto et al., 2005b). More recently, other authors have also supported that LC activation promotes DA release in the thalamus and hippocampus, contributing to stress and cognitive functions (Smith and Greene, 2012; Kempadoo et al., 2016; Yamasaki and Takeuchi, 2017; Beas et al., 2018).

In view of the dense noradrenergic projection network, it is easy to understand the implication of this nucleus in many physiological functions and pathological conditions. Experimental preclinical models have demonstrated the implication of the LC in arousal, cognition, anxiety, depression, pain, attention, and locomotor control (Aston-Jones and Bloom, 1981; Carter et al., 2010; Curtis et al., 2012; Sara and Bouret, 2012; Chandler et al., 2014; McCall 
et al., 2015; Szot et al., 2016; Benarroch, 2017; Hirschberg et al., 2017; McCall et al., 2017; Beas et al., 2018; Breton-Provencher and Sur, 2019; Llorca-Torralba et al., 2019). The availability of new technologies, as opto- and chemogenetics, that allow efficient activation/inhibition of specific anatomical projections or cellular subtypes, has provided a better understanding of those functions and unraveled that the LC is a more heterogeneous nucleus than previously proposed. Interestingly many of the pathological situations triggered by the dysfunction of the LC are present in $\mathrm{PD}$, stressing the role of this nucleus in the development and management of the non-motor complications of the disease.

\section{NORADRENERGIC DYSFUNCTION IN PARKINSON'S DISEASE}

\section{Preclinical Evidence}

In the last decades, researchers have shown increasing interest in further understanding the pathophysiological basis of the nonmotor symptoms present in PD with special focus on the noradrenergic system. In the preclinical studies, viral-vectorinduced, gene-mutated, or neurotoxin-based animal models are regularly used although the vast majority of the data come from these latter ones.

Anatomical studies using the unilaterally 6-hydroxydopamine (6-OHDA)-lesioned rat model show that the number of LC neurons is not affected by the DA loss (Miguelez et al., 2011b; Ostock et al., 2018) but NA levels in different projection areas are variably decreased. In the prefrontal cortex of the lesioned hemisphere, some authors found unchanged (Delaville et al., 2012a; Delaville et al., 2012b) or reduced NA concentrations (Shin et al., 2014; Ostock et al., 2018). Similarly, other areas with sparse noradrenergic innervation, as the striatum, show unchanged or lower NA levels (Shin et al., 2014; Ostock et al., 2018). Bilateral models of 6-OHDA show, however, more robust NA deficits in the cortex and striatum (Vieira et al., 2019). 1-Methyl-4-phenyl-1,2,3,6-tetrahydropyridine (MPTP)-treated monkeys exhibit clear noradrenergic damage, including LC cell loss, lower NA concentrations in several brain regions, and reduced noradrenergic innervation of the SNc and the subthalamic nucleus (Pifl et al., 1991; Masilamoni et al., 2017). Some publications have also reported low NA striatal and cortical tissue content in MPTP mice (Luchtman et al., 2009; Nayyar et al., 2009; Ando et al., 2018). Indeed, MPTP reproduces better than 6-OHDA the heterogeneous neuronal damage produced in $\mathrm{PD}$, as recently shown by a publication using matrix-assisted laser desorptionionization mass spectrometry (Kadar et al., 2014). Evidence regarding the integrity of the noradrenergic system in transgenic mice models of PD is more scarce but also stresses noradrenergic impairment. Thus, reduced tyrosine hydroxylase positive cells and $\alpha$-synuclein aggregations in the LC have been demonstrated in PINK1 knockout rats (Grant et al., 2015; Cullen et al., 2018), LRRK, and parkin knockout mice (Von Coelln et al., 2004; Giaime et al., 2017). However, in transgenic mice overexpressing human A53T $\alpha-$ synuclein, although having lower NA levels at the level of the striatum, olfactory bulb, and spinal cord, TH positive cells in the LC expressed modest $\alpha$-synuclein aggregates but remained intact in number (Giasson et al., 2002; Sotiriou et al., 2010). These noradrenergic dysfunctions are accompanied by behavioral deficits, such as early vocalization and swallowing deficits.

It is also interesting to stress that in parkinsonian conditions, the noradrenergic system may contribute in some extent to the loss of dopaminergic function. In animals lesioned with 6OHDA, noradrenergic transporter (NET) are increased possibly for compensating for the severe DA loss (Chotibut et al., 2012). Indeed, NET can reuptake not only NA but also DA in those regions with sparse DA innervation (Morón et al., 2002). In this line, some publications support that in absence of DA transporters, NET reuptakes L-DOPA-derived DA in the striatum and other areas, playing a possible role in L-DOPA induced dyskinesia (LID), as later discussed.

Apart from the anatomical and neurochemical changes, few electrophysiological studies using anaesthetized 6-OHDA lesioned animals, have revealed that experimental DA degeneration also impacts LC neuron basal activity and its response to antidepressant agents in parkinsonian rodents. Regarding the electrophysiological changes, increased and decreased activity was reported by different authors (Wang et al., 2009; Miguelez et al., 2011a; Miguelez et al., 2011b). This discrepancy may rely in methodological differences that could imply direct noradrenergic damage produced by the neurotoxins (Szot et al., 2016). On the other hand, in control rats, serotonergic and noradrenergic antidepressants interact with L-DOPA when administered together (see below). Using the forced swimming test, control rats subchronically treated with LDOPA and fluoxetine showed reduced efficacy of the antidepressant drug, while coadministration of the NET blocker reboxetine and L-DOPA provided the opposite effect (Miguelez et al., 2013). At the behavioral level, regardless inconsistencies found through the scientific publications, parkinsonian animals tend to mimic the human symptomatology showing motor but also non-motor impairments (Titova et al., 2017). An array of studies report that rodents lesioned with 6-OHDA or MPTP show anxious and depressive behavior, pain, cognitive, and sleep disturbances (Monaca et al., 2004; Pérez et al., 2009; BerghauzenMaciejewska et al., 2014; Vo et al., 2014; Kamińska et al., 2017; Charles et al., 2018; Campos et al., 2019; Domenici et al., 2019), more notably in bilateral models of the disease (Ferro et al., 2005; Tadaiesky et al., 2008; Santiago et al., 2010; Bonito-Oliva et al., 2014; Vieira et al., 2019). Although the participation of other nuclei cannot be ruled out, the role of the LC in the mentioned functions is widely accepted.

Although preclinical data to large extent support the noradrenergic affection in parkinsonian models, several discrepancies exist, which may be due to methodological variations. In this regard, especially when using the neurotoxin 6-OHDA, it should be considered that lesion protocols vary considerably among the studies, including key steps like animal age, toxin dose and injection site, magnitude of the lesions, and administration of the non-selective NET blocker desipramine to protect noradrenergic neurons from the 6-OHDA toxicity. 
Genetic and $\alpha$-synuclein based models are less often used with considerable results variation among the studies. The use of other neurotoxins as MPTP seems to provide results that are more consistent.

\section{Clinical Evidence}

In line with the aforementioned findings reported in animal models of PD, there is substantial evidence showing degeneration of the noradrenergic system in PD patients. Numerous anatomical post mortem studies in PD brains have documented a moderate to severe cell loss (around 30-90\%) and Lewy body pathology in the LC, equal in magnitude throughout the rostral-caudal parts of the nucleus (Gaspar and Gray, 1984; Chan-Palay and Asan, 1989; German et al., 1992; Bertrand et al., 1997; Zarow et al., 2003; McMillan et al., 2011). Specifically, neuromelanin-containing medium-size LC neurons present somatic and dendritic alterations, whereas smaller nonnoradrenergic LC cells do not show severe pathological changes (Patt and Gerhard, 1993).

Although in vivo positron emission tomography imaging studies using non-specific ligands failed to identify the noradrenergic damage, more recent neuromelanin-sensitive magnetic resonance studies have found progressive loss of the LC signal in both idiopathic and genetic PD patients and even a lower signal in those PD patients with depressive symptoms (Sasaki et al., 2006; Castellanos et al., 2015; Schwarz et al., 2017; Wang et al., 2018). ${ }^{18}$ F-dopa positron emission tomography imaging, as an index of monoaminergic nerve terminal function, have also demonstrated a reduced uptake in the LC, indicating progressive loss of noradrenergic terminal function (Pavese et al., 2011).

While the relationship between $\alpha$-synuclein accumulation and neuronal death is not fully understood, it has been proposed that this protein burden may lead to neuronal dysfunction/degeneration and, therefore, impair neurotransmission (Espay et al., 2014). As explained before, Braak and colleagues established six levels of degeneration over the course of the disease where the noradrenergic impairment would occur earlier than the dopaminergic one and the subsequent primary motor symptoms. It has further been proposed that $\alpha$-synuclein pathology in the LC not only precedes, but may also be of greater magnitude than that occurring in the $\mathrm{SNc}$, a finding that persists across disease stages (Zarow et al., 2003). These results suggest that LC dysfunction may directly contribute to disease onset and progression rather than be a collateral consequence.

Consistent with LC neuron loss and degeneration, there is a decreased noradrenergic innervation of LC target structures, including the prefrontal and motor cortex, striatum, thalamus, hypothalamus, and cerebellum (Kish et al., 1984; Shannak et al., 1994; Pavese et al., 2011; Pifl et al., 2012; Sommerauer et al., $2018 b)$. The atrophy of tyrosine hydroxylase-containing axons is not restricted to the central nervous system, and a prominent loss of noradrenergic innervations of the peripheral autonomic system has been demonstrated, including in the left cardiac ventricle (Hakusui et al., 1994; Takatsu et al., 2000; Slaets et al., 2015).
Although plasma NA levels are elevated in de novo PD patients (Ahlskog et al., 1996), neurochemical studies have reported lower levels of the neuronal NA metabolite dihydroxyphenylglycol in the cerebrospinal fluid (Goldstein et al., 2012), as well as marked reduction of DA-betahydroxylase activity, an enzyme responsible for hydroxylation of DA to NA, in parkinsonian patients (Hurst et al., 1985; O'Connor et al., 1994). Regarding changes in adrenergic receptors in $\mathrm{PD}$, an in vitro autoradiographic study showed upregulation of $\alpha_{1}$ - and $\beta_{1}$ - and reduced density of $\alpha_{2}$ adrenoceptors in the prefrontal cortex of post mortem parkinsonian patients (Cash et al., 1984).

Despite some discrepancies in animal models, both preclinical and clinical studies support the notion that the noradrenergic system is impaired in parkinsonism. This is important for understanding the complexity of the neurodegenerative process and should be taken into account when administering drugs whose pharmacological effect relies on the integrity of this system.

\section{CLINICAL IMPLICATIONS OF NORADRENERGIC DYSFUNCTION IN PD}

The degeneration of the noradrenergic system in the CNS and periphery occurring in PD is associated with a broad spectrum of non-motor symptoms that encompass autonomic, behavioral, and cognitive parameters. The appearance of these symptoms and signs cannot be just attributed to an alteration in the functioning of the noradrenergic system, as they are also known to be associated with deficits in other neurotransmission systems such as cholinergic, serotonergic, GABAergic, or glutamatergic (Schapira et al., 2017). However, in this review, we will focus on non-motor complications appearing in the prodromal phase of the disease that, apart from other neurotransmitters' abnormalities, implicate malfunctioning of LC neurons.

In accordance with predicted Braak's stages, the different clinical features due to noradrenergic dysfunction can be observed along the progression of the disease (Halliday et al., 2011) and, often appear before motor symptoms onset. Detecting noradrenergic impairment could be used as a diagnostic biomarker for early detection of the neurodegeneration, providing an opportunity for intervention with diseasemodifying therapies (Betts et al., 2019).

\section{Autonomic Disturbances}

Sympathetic autonomic dysfunction is a common clinical feature of $\mathrm{PD}$ and may precede motor symptomatology, becoming more prevalent as the disease progresses (Schapira et al., 2017). The most common dysautonomic symptoms are orthostatic hypotension, urogenital dysfunction, and constipation (MartinezMartin et al., 2015), but PD patients can also suffer fatigue, thermoregulatory dysregulation, excessive perspiration, or postural light-headedness. Autonomic dysfunction has a heterogeneous manifestation and its progression is not predictable, however, it is associated with reduced autonomy and a decline in quality of life, 
regardless of severity or duration of the disease (Leclair-Visonneau et al., 2018). The orthostatic hypotension affects 30-58\% of PD patients (Goldstein, 2006) and has been linked to peripheral sympathetic cardiovascular denervation and also in a certain degree to central autonomic involvement. PD patients with defined symptomatic orthostatic hypotension exhibit decreased LC neuromelanin signal on magnetic resonance studies (Sommerauer et al., 2018a) and low plasma levels of NA, which is associated with both supersensitivity of vascular adrenergic receptors and an up-regulation of platelet $\alpha_{2}$-adrenoceptors (Senard et al., 1990). As a consequence of a reduced capacity to adapt the peripheral vasculature and cerebral perfusion pressure PD patients can often manifest postural light-headedness and syncope (Sharabi et al., 2008). Constipation and prolonged gastrointestinal transit time affect more than $80 \%$ of PD patients and, in some cases, may lead to megacolon (for review see Cersosimo and Benarroch, 2008). Although defecation dysfunction seems to be multifactorial, one of the proposed pathophysiological mechanisms is the accumulation of $\alpha$-synuclein immunoreactive Lewy bodies in sympathetic ganglia (Wakabayashi and Takahashi, 1997). Urinary and sexual dysfunctions are also late features of PD related to degeneration of brain regions that innervate the bladder, among them the LC (Micieli et al., 2003; Park and Stacy, 2009).

\section{Sleep Disorders}

Sleep disturbances are among the most frequent PD symptoms, affecting some $60-98 \%$ of patients (Stacy, 2002). Common sleep disorders include excessive daytime somnolence, nocturnal wakefulness, sleep attacks, REM sleep behavior disorder, or restless leg syndrome. All these sleep impairments can be early premotor manifestations and related to LC dysfunction as underlying mechanism, since this nucleus contributes to the control of arousal and sleep-wake cycle (Carter et al., 2010). In fact, post mortem examinations of patients with REM sleep behavior disorder without motor symptoms revealed neuronal loss and Lewy bodies in the LC (Uchiyama et al., 1995). A recent magnetic resonance study further linked LC neuromelanin levels with amount of REM sleep without atonia in PD patients (Sommerauer et al., 2018a). Clinical management of sleep disorders in PD is complex because most of the antiparkinsonian drugs can alter sleep architecture and induce sleepiness as a side effect. Nevertheless clonazepam or melatonin are often prescribed (Gagnon et al., 2006).

\section{Depression}

Depression affects up to $40 \%$ of PD patients and may precede the onset of motor symptomatology (Cummings, 1992; Shiba et al., 2000; Cummings et al., 2019). There is strong evidence for a correlation between noradrenergic function and depression in PD patients. In fact, neuroimaging and neuropathological studies have demonstrated reduced LC projections to limbic brain areas (cingulate cortex, thalamus, ventral striatum, or amygdala), as well as gliosis and cell loss at LC level, which was more pronounced in patients with higher frequency of depression or anxiety (Remy et al., 2005; Frisina et al., 2009). As in major depression, selective serotonin reuptake inhibitors, tricyclic antidepressants, serotonin and NA reuptake inhibitors, and monoamine oxidase inhibitors are used in the pharmacotherapy, with partial effect, probably influenced by the neurodegeneration of the serotonergic and noradrenergic systems (Ryan et al., 2019). The use of antidepressant that do not target monoaminergic systems may potentially offer benefit in these patients (Vanle et al., 2018).

\section{Cognitive Manifestations}

The loss of LC neurons and decreased noradrenergic innervation of forebrain targets are associated with cognitive dysfunction in PD (Cash et al., 1987; Rommelfanger and Weinshenker, 2007; Vazey and Aston-Jones, 2012; Sommerauer et al., 2018a). In early $\mathrm{PD}$, subtle cognitive deficits include difficulty in executing functioning, particularly cognitive flexibility, which is the capacity to update and redirect attention when the environmental or homeostatic conditions change. Flexibility in cognitive processing is an essential function of prefrontal cortex and it has been proposed that loss of prefrontal noradrenergic input may contribute to this prodromal cognitive deficit (Vazey and Aston-Jones, 2012). In late stage PD, dementia can occur with a prevalence of $24-31 \%$ (Aarsland et al., 2005). Although dementia in PD is related to a substantial reduction in cortical cholinergic markers, there is also evidence for a more severe loss of noradrenergic input from the LC to cortical areas (Chan-Palay and Asan, 1989). The severity of dementia has been linked to the loss of LC neurons in some studies (Zweig et al., 1993; Del Tredici and Braak, 2013; Li et al., 2019).

\section{NORADRENALINE, NEUROINFLAMMATION, AND NEUROPROTECTION}

It is important to mention that NA might protect DA neurons from damage and therefore, integrity of the noradrenergic system may condition the progression of the disease. In this sense, preclinical data from MPTP mice and marmosets suggest that damaging the LC leads to a loss of DA neurons in the SNc followed by more pronounced motor deficits (Mavridis et al., 1991; Marien et al., 1993; Bing et al., 1994; Fornai et al., 1995; Fornai et al., 1997; Yao et al., 2015; Li Y. et al., 2018). Conversely, the damage produced by MPTP is reduced when the synthesis of NA is boosted (Kilbourn et al., 1998; Archer, 2016) or the NET is knocked out (Rommelfanger et al., 2004). A recent publication using mutant mice characterized by the progressive degeneration of dopaminergic neurons demonstrated that chronic pharmacological NET blockade ameliorates such degeneration and the subsequent motor impairment (Kreiner et al., 2019). Peripheral administration of the NET blocker atomoxetine also reduced DA damage in a lipopolysaccharide inflammatory rat model of PD (Yssel et al., 2018). Direct noradrenergic damage by the administration of the neurotoxin $\mathrm{N}$-(2-chloroethyl)- $\mathrm{N}$-ethyl2-bromobenzylamine (or DSP-4) also produces motor deficits and DA cell loss in control rats (Af Bjerkén et al., 2019). In another recent publication, DSP-4 developed motor and nonmotor symptoms in control mice and exacerbated motor disability in mice rendered parkinsonian by the injection of lipopolysaccharide (Song et al., 2019). Some studies performed 
in 6-OHDA lesioned rodents also suggest that noradrenergic lesions in parkinsonian rats augment dopaminergic neuron vulnerability (Ostock et al., 2014) leading to lower DA levels (Srinivasan and Schmidt, 2003) and worsening motor performance (Srinivasan and Schmidt, 2003; Srinivasan and Schmidt, 2004; Wang et al., 2010; Shin et al., 2014; Ostock et al., 2018). Other studies using the same 6-OHDA model failed, however, to reproduce the latter findings (Delaville et al., 2012a; Guimarães et al., 2013; Ostock et al., 2014; Shin et al., 2014).

The mechanism underlying the neuroprotective effect of NA on DA degeneration is not well understood, although several lines of evidence point at the anti-inflammatory properties of NA as one factor responsible of such an effect. Both PD patients and animal models of the disease show reactive astrogliosis, astrocytic dysfunction, and microglial activation, which has been proposed as the origin of neuroinflammation (Ouchi et al., 2005; Gerhard et al., 2006; Glass et al., 2010; Terada et al., 2016; Liu et al., 2017; Tsutsumi et al., 2019). Importantly, by controlling microglial activation NA is able to halt the damage of dopaminergic neurons. Studies performed in cell cultures and animal models suggest that NA suppresses neuroinflammation by acting, at least in part, on $b_{2}$-adrenergic receptors, which are highly expressed in glial cells (Mori et al., 2002; Tanaka et al., 2002; Yao et al., 2015). Low concentrations of NA or long acting $\beta_{2}$-agonists are able to inhibit the microglial production and release of chemokines, interleucines, tumor necrosis factor (TNF- $\alpha$ ), superoxide or nitric oxide, among others, (Mori et al., 2002; McNamee et al., 2010a; Qian et al., 2011) or to stimulate the synthesis of interleukin-1 receptor antagonists (McNamee et al., 2010b). Pharmaceutical strategies for increasing NA levels also attenuate nigral microglial activation and ameliorate the behavioral deficits in parkinsonian rats (Yssel et al., 2018). Other authors have also proposed that in addition to the $\beta_{2^{-}}$ mediated mechanisms, NA can impact inflammation by inhibiting NADPH oxidase-generated superoxide (Jiang et al., 2015). Additionally, $\beta_{2}$-agonists and NET inhibitors can also induce release of neurotrophic factors from astrocytes promoting neuroprotection and regeneration (Yssel et al., 2018).

By contrast, NA deficit accelerates dopaminergic neurodegeneration by promoting inflammation, diminishing neurotrophic factors and promoting oxidation in the SN (Yao et al., 2015; Af Bjerkén et al., 2019). In this sense, a recent publication observed that additional lesion of the LC in animal models of PD promotes enhanced release of interleukins and cytokines, likely due to an incorrect microglial function, and aggravates DA neuron degeneration (Yao et al., 2015) although some authors fails to confirm this cell loss (Iravani et al., 2014). As commented before, combined dual NA/DA lesions lead to more severe phenotype including motor and non-motor symptomatology, probably due to the higher inflammatory response and faster cell loss (Bharani et al., 2017; Song et al., 2019). The implication of NA in neuroinflamation and neuroprotection could have an important translational impact in the clinic. In this sense, a long-term prospective observatory study has reported that those patients with chronic respiratory diseases, that are chronically treated with $\beta_{2}$-adrenergic agonists may have a lower probability of developing PD (Mittal et al., 2017). One of the reasons for this neuroprotective effect may not only rely on microglial activation, but also on the ability of $b_{2^{-}}$ adrenoceptors to down regulate expression of human $\alpha$ synuclein genes and moderate protein expression. When looking for new neuroprotective therapies, it may be relevant to assure a good NA tone for minimizing the contribution of neuroinflammation to the neuropathology.

\section{L-DOPA AND THE NORADRENERGIC SYSTEM}

L-DOPA is still considered the most efficient anti-parkinsonian drug. It is a metabolic precursor of NA through its decarboxylation into $\mathrm{DA}$ by the aromatic amino acid decarboxylase and the $\beta$-hydroxylation of DA by the DA betahydroxylase. Unfortunately, L-DOPA is poorly effective against non-motor symptoms, does not control some later-onset motor problems like freezing or "wearing-off" fluctuations, and its longterm use is associated with dyskinesia and hallucinations (Olanow et al., 2009; Hirao et al., 2015). The contribution of the noradrenergic system to LID has been investigated in animal models using NA/DA neurotoxic lesions. Although some studies report no implication of the noradrenergic system (Pérez et al., 2009; Ostock et al., 2014; Ostock et al., 2018), others have demonstrated that additional noradrenergic lesion worsens dyskinetic movements in parkinsonian rodents chronically treated with L-DOPA (Fulceri et al., 2007; Miguelez et al., 2011b; Shin et al., 2014). Interestingly, in one study, the authors induced the noradrenergic lesion to already dyskinetic animals, showing an increase in the duration of the dyskinetic effect of L-DOPA probably due to impaired striatal DA clearance (Miguelez et al., 2011b).

Some noradrenergic drugs have proven antidyskinetic properties in experimental animal models of LID. The $\alpha_{2 A^{-}}$ adrenoceptor antagonist idazoxan, reduced LID, and delayed their onset without compromising the motor score in MPTPtreated monkeys. Idazoxan prevented LID appearance while increasing the locomotor response to L-DOPA (Henry et al., 1999; Grondin et al., 2000; Fox et al., 2001). Additional $\alpha_{2 A^{-}}$ adrenoceptor antagonists have proven similar antidyskinetic properties (Gomez-Mancilla and Bédard, 1993; Henry et al., 1999; Grondin et al., 2000; Savola et al., 2003; Fox and Brotchie, 2010). Other noradrenergic drugs, as the $\beta$ adrenergic receptor antagonist propranolol and the $\alpha_{2}$-receptor agonist clonidine also showed antidyskinetic effects in MPTPtreated monkeys, at the cost of reducing the antiparkinsonian efficacy (Gomez-Mancilla and Bédard, 1993). Experiments performed in 6-OHDA lesioned rats support the prodyskinetic action of the $\alpha_{2}$-antagonist atipamezole and the antidyskinetic effect of propranonol, clonidine, or idazoxan, which did not worsen motor performance (Dekundy et al., 2007; Gerlach et al., 2013; Bhide et al., 2015; Ostock et al., 2015). These findings 
suggest that the limited though beneficial effect of clonidine on LID is probably indirect due to the stimulation of somatodendritic $\alpha_{2}$-receptors, which inhibit noradrenergic neuronal activity and NA release. Some authors also suggest that the antidyskinetic effect of clonidine may be related to its sedative properties (Gerlach et al., 2013). Conversely, the antidyskinetic action of idazoxan, even if it enhances brain NA release by antagonizing $\alpha_{2}$ autoreceptors, could be related to the blockade of $\alpha_{2}$-receptors expressed by NA receptive cells at terminal levels. In any case, the overall picture is complex due to the involvement of the other adrenergic receptor subtypes in LID. The resulting effect of an overall increase in NA extracellular on LID is thus uncertain. In contrast to the beneficial effect of reboxetine (Shin et al., 2014), other NET inhibitors including desipramine have been reported to aggravate LID (Arai et al., 2008; Chotibut et al., 2014; Conti et al., 2016).

As mentioned above, noradrenergic mechanisms are involved in non-motor symptoms and shape the responses to other medications such as antidepressant drugs (Eskow Jaunarajs et al., 2010; Eskow Jaunarajs et al., 2011; Miguelez et al., 2011b; Miguelez et al., 2013). Noradrenergic neurons may also be involved in the effects of L-DOPA, but the preclinical data are not clear. For instance, participation of noradrenergic neurons in the ability of L-DOPA to enhance DA extracellular levels is likely an indirect effect that requires the dorsal raphe nucleus (Tanaka et al., 1999; Navailles et al., 2010; Navailles and De Deurwaerdère, 2012; De Deurwaerdère et al., 2017; Miguelez et al., 2017). In dyskinetic rats, lesion of noradrenergic terminals or neurons did not reduce L-DOPA-stimulated extracellular levels of DA in the striatum (Navailles et al., 2014; Ostock et al., 2018). However, the noradrenergic lesion enhanced the effect of L-DOPA in extrastriatal regions in part due to the loss of clearance of extracellular DA by noradrenergic fibers bearing NET (Navailles et al., 2014). Another study found that the noradrenergic lesion with DSP-4 potentiates L-DOPA-induced rotations, although this behavioral effect is not directly related to DA extracellular levels (Pérez et al., 2007). Evidence suggests that the noradrenergic system participates in the effect of L-DOPA, but preclinical data are difficult to extrapolate to PD patients because the noradrenergic fibers, at least from the LC, are damaged (see above). It is also important to bear in mind that extracellular striatal DA levels induced by L-DOPA in the striatum neither parallel motor effects nor abnormal motor effects (De Deurwaerdère et al., 2017).

Although behavioral data support that noradrenergic drugs can modulate the effect of L-DOPA, the potential effect of LDOPA on NA content or neuron activity is less clear. In the LC, low doses of L-DOPA did not alter the electrical tonic activity of noradrenergic neurons in control rats (Miguelez et al., 2013). Post mortem data vary, reporting no effect, or a decrease in NA tissue concentration in response to L-DOPA administration depending on the dose regimen and the brain region studied (for review see De Deurwaerdère et al., 2017). Acute or chronic L-DOPA increased NA tissue level in the prefrontal cortex of normal macaques, but the same regimen decreased NA tissue level in the prefrontal cortex and the amygdala of MPTP-treated monkeys whether they were dyskinetic or not (Engeln et al., 2015). The only difference regarding NA tissue levels between non-dyskinetic and dyskinetic monkeys was found at the level of the motor cortex. Studies on L-DOPA-evoked extracellular levels of NA also show inconclusive results. In this regard, the latest publications have reported a substantial increase in striatal NA release after L-DOPA administration (Wang et al., 2014; Ostock et al., 2018). However, in one study NA levels were still excessive after noradrenergic neurons were destroyed (Ostock et al., 2018). It is likely that other electrochemically active compounds were confounding the chromatograms (Chagraoui et al., 2019). Other data indicate that L-DOPA either inhibits or does not alter NA release in the cortex (Dayan and Finberg, 2003; Pascucci et al., 2012).

\section{CONCLUSION}

The identification of noradrenergic mechanisms in PD is crucial for understanding autonomic functions and non-motor symptomatology, and drugs that target this system may have a beneficial impact in the quality of life of the patients. One major difficulty is to extrapolate the results from animal models to patients where those alterations are variable and depend on the stage of the disease. Meanwhile, the involvement of the noradrenergic system in L-DOPA induced therapeutic effects is controversial, and noradrenergic strategies to limit the side effects accompanying anti-parkinsonian drugs are still not firmly established. In summary, and taking into account that noradrenergic system pathophysiology is a common feature of $\mathrm{PD}$ with other neurodegenerative diseases, such as Alzheimer's disease or atypical neurodegenerative dementias, maintenance of this system integrity may provide a common viable therapeutic option as neurodegenerative diseases-modifying strategy.

\section{AUTHOR CONTRIBUTIONS}

All authors contributed to writing the manuscript and approved the final version.

\section{FUNDING}

This study was supported by grants from the Basque Government (PIBA 2019-38, IT1345-19), UPV/EHU (PPGA19/15), and Spanish Government (SAF2016-77758-R [AEI/FEDER, UE]). EP-R has a fellowship from the Basque Country and SV-S from the UPV/EHU. 


\section{REFERENCES}

Aarsland, D., Zaccai, J., and Brayne, C. (2005). A systematic review of prevalence studies of dementia in Parkinson's disease. Mov. Disord. Off. J. Mov. Disord. Soc 20, 1255-1263. doi: 10.1002/mds.20527

Af Bjerkén, S., Stenmark Persson, R., Barkander, A., Karalija, N., PelegrinaHidalgo, N., Gerhardt, G. A., et al. (2019). Noradrenaline is crucial for the substantia nigra dopaminergic cell maintenance. Neurochem. Int. 131, 104551. doi: 10.1016/j.neuint.2019.104551

Ahlskog, J. E., Uitti, R. J., Tyce, G. M., O’Brien, J. F., Petersen, R. C., and Kokmen, E. (1996). Plasma catechols and monoamine oxidase metabolites in untreated Parkinson's and Alzheimer's diseases. J. Neurol. Sci. 136, 162-168. doi: 10.1016/0022-510x(95)00318-v

Amaral, D. G., and Sinnamon, H. M. (1977). The locus coeruleus: neurobiology of a central noradrenergic nucleus. Prog. Neurobiol. 9, 147-196. doi: 10.1016/ 0301-0082(77)90016-8

Ando, R., Choudhury, M. E., Yamanishi, Y., Kyaw, W. T., Kubo, M., Kannou, M., et al. (2018). Modafinil alleviates levodopa-induced excessive nighttime sleepiness and restores monoaminergic systems in a nocturnal animal model of Parkinson's disease. J. Pharmacol. Sci. 136, 266-271. doi: 10.1016/ j.jphs.2018.03.005

Arai, A., Tomiyama, M., Kannari, K., Kimura, T., Suzuki, C., Watanabe, M., et al. (2008). Reuptake of L-DOPA-derived extracellular DA in the striatum of a rodent model of Parkinson's disease via norepinephrine transporter. Synap. N. Y. N 62, 632-635. doi: 10.1002/syn.20535

Archer, T. (2016). Noradrenergic-Dopaminergic Interactions Due to DSP-4MPTP Neurotoxin Treatments: Iron Connection. Curr. Top. Behav. Neurosci. 29, 73-86. doi: 10.1007/7854_2015_411

Aston-Jones, G., and Bloom, F. E. (1981). Activity of norepinephrine-containing locus coeruleus neurons in behaving rats anticipates fluctuations in the sleepwaking cycle. J. Neurosci. Off. J. Soc Neurosci. 1, 876-886. doi: 10.1523/ JNEUROSCI.01-08-00876.1981

Aston-Jones, G., Ennis, M., Pieribone, V. A., Nickell, W. T., and Shipley, M. T. (1986). The brain nucleus locus coeruleus: restricted afferent control of a broad efferent network. Science 234, 734-737. doi: 10.1126/science.3775363

Aston-Jones, G., Zhu, Y., and Card, J. P. (2004). Numerous GABAergic afferents to locus ceruleus in the pericerulear dendritic zone: possible interneuronal pool. J. Neurosci. Off. J. Soc Neurosci. 24, 2313-2321. doi: 10.1523/JNEUROSCI.5339-03.2004

Baldo, B. A., Daniel, R. A., Berridge, C. W., and Kelley, A. E. (2003). Overlapping distributions of orexin/hypocretin- and dopamine-beta-hydroxylase immunoreactive fibers in rat brain regions mediating arousal, motivation, and stress. J. Comp. Neurol. 464, 220-237. doi: 10.1002/cne.10783

Beas, B. S., Wright, B. J., Skirzewski, M., Leng, Y., Hyun, J. H., Koita, O., et al. (2018). The locus coeruleus drives disinhibition in the midline thalamus via a dopaminergic mechanism. Nat. Neurosci. 21, 963-973. doi: 10.1038/s41593018-0167-4

Benarroch, E. E. (2017). Locus coeruleus. Cell Tissue Res. 373 (1), 221-232. doi: 10.1007/s00441-017-2649-1

Berghauzen-Maciejewska, K., Kuter, K., Kolasiewicz, W., Głowacka, U., Dziubina, A., Ossowska, K., et al. (2014). Pramipexole but not imipramine or fluoxetine reverses the "depressive-like" behaviour in a rat model of preclinical stages of Parkinson's disease. Behav. Brain Res. 271, 343-353. doi: 10.1016/j.bbr.2014.06.029

Berridge, C. W., and Waterhouse, B. D. (2003). The locus coeruleus-noradrenergic system: modulation of behavioral state and state-dependent cognitive processes. Brain Res. Rev. 42, 33-84. doi: 10.1016/S0165-0173(03)00143-7

Berridge, C. W., Stratford, T. L., Foote, S. L., and Kelley, A. E. (1997). Distribution of dopamine beta-hydroxylase-like immunoreactive fibers within the shell subregion of the nucleus accumbens. Synap. N. Y. N27, 230-241. doi: 10.1002/ (SICI) 1098-2396(199711)27:3<230::AID-SYN8>3.0.CO;2-E

Bertrand, E., Lechowicz, W., Szpak, G. M., and Dymecki, J. (1997). Qualitative and quantitative analysis of locus coeruleus neurons in Parkinson's disease. Folia Neuropathol. 35, 80-86.

Betts, M. J., Kirilina, E., Otaduy, M. C. G., Ivanov, D., Acosta-Cabronero, J., Callaghan, M. F., et al. (2019). Locus coeruleus imaging as a biomarker for noradrenergic dysfunction in neurodegenerative diseases. Brain 142, 25582571. doi: 10.1093/brain/awz193

Bharani, K. L., Derex, R., Granholm, A.-C., and Ledreux, A. (2017). A noradrenergic lesion aggravates the effects of systemic inflammation on the hippocampus of aged rats. PloS One 12, e0189821. doi: 10.1371/ journal.pone.0189821

Bhide, N., Lindenbach, D., Barnum, C. J., George, J. A., Surrena, M. A., and Bishop, C. (2015). Effects of the beta-adrenergic receptor antagonist Propranolol on dyskinesia and L-DOPA-induced striatal DA efflux in the hemi-parkinsonian rat. J. Neurochem. 134, 222-232. doi: 10.1111/jnc.13125

Bing, G., Zhang, Y., Watanabe, Y., McEwen, B. S., and Stone, E. A. (1994). Locus coeruleus lesions potentiate neurotoxic effects of MPTP in dopaminergic neurons of the substantia nigra. Brain Res. 668, 261-265. doi: 10.1016/00068993(94)90534-7

Bonito-Oliva, A., Masini, D., and Fisone, G. (2014). A mouse model of non-motor symptoms in Parkinson's disease: focus on pharmacological interventions targeting affective dysfunctions. Front. Behav. Neurosci. 8, 290. doi: 10.3389/ fnbeh.2014.00290

Braak, H., and Del Tredici, K. (2016). Potential Pathways of Abnormal Tau and $\alpha$ Synuclein Dissemination in Sporadic Alzheimer's and Parkinson's Diseases. Cold Spring Harb. Perspect. Biol. 8, a023630. doi: 10.1101/cshperspect.a023630

Braak, H., Del Tredici, K., Rüb, U., de Vos, R. A. I., Jansen Steur, E. N. H., and Braak, E. (2003). Staging of brain pathology related to sporadic Parkinson's disease. Neurobiol. Aging 24, 197-211. doi: 10.1016/S0197-4580(02)00065-9

Braak, H., Ghebremedhin, E., Rüb, U., Bratzke, H., and Del Tredici, K. (2004). Stages in the development of Parkinson's disease-related pathology. Cell Tissue Res. 318, 121-134. doi: 10.1007/s00441-004-0956-9

Breton-Provencher, V., and Sur, M. (2019). Active control of arousal by a locus coeruleus GABAergic circuit. Nat. Neurosci. 22, 218-228. doi: 10.1038/s41593018-0305-Z

Campos, A. C. P., Berzuino, M. B., Hernandes, M. S., Fonoff, E. T., and Pagano, R. L. (2019). Monoaminergic regulation of nociceptive circuitry in a Parkinson's disease rat model. Exp. Neurol. 318, 12-21. doi: 10.1016/j.expneurol.2019.04.015

Carter, M. E., Yizhar, O., Chikahisa, S., Nguyen, H., Adamantidis, A., Nishino, S., et al. (2010). Tuning arousal with optogenetic modulation of locus coeruleus neurons. Nat. Neurosci. 13, 1526-1533. doi: 10.1038/nn.2682

Cash, R., Ruberg, M., Raisman, R., and Agid, Y. (1984). Adrenergic receptors in Parkinson's disease. Brain Res. 322, 269-275. doi: 10.1016/0006-8993(84) 90117-3

Cash, R., Dennis, T., L'Heureux, R., Raisman, R., Javoy-Agid, F., and Scatton, B. (1987). Parkinson's disease and dementia: norepinephrine and dopamine in locus ceruleus. Neurology 37, 42-46. doi: 10.1212/wnl.37.1.42

Castellanos, G., Fernández-Seara, M. A., Lorenzo-Betancor, O., Ortega-Cubero, S., Puigvert, M., Uranga, J., et al. (2015). Automated neuromelanin imaging as a diagnostic biomarker for Parkinson's disease. Mov. Disord. Off. J. Mov. Disord. Soc 30, 945-952. doi: 10.1002/mds.26201

Cersosimo, M. G., and Benarroch, E. E. (2008). Neural control of the gastrointestinal tract: implications for Parkinson disease. Mov. Disord. Off. J. Mov. Disord. Soc 23, 1065-1075. doi: 10.1002/mds.22051

Chagraoui, A., Boulain, M., Juvin, L., Anouar, Y., Barrière, G., and Deurwaerdère, P. D. (2019). L-DOPA in Parkinson's Disease: Looking at the "False" Neurotransmitters and Their Meaning. Int. J. Mol. 21. doi: 10.3390/ijms21010294

Chandler, D. J., Gao, W.-J., and Waterhouse, B. D. (2014). Heterogeneous organization of the locus coeruleus projections to prefrontal and motor cortices. Proc. Natl. Acad. Sci. U. S. A. 111, 6816-6821. doi: 10.1073/pnas.1320827111

Chan-Palay, V., and Asan, E. (1989). Alterations in catecholamine neurons of the locus coeruleus in senile dementia of the Alzheimer type and in Parkinson's disease with and without dementia and depression. J. Comp. Neurol. 287, 373392. doi: $10.1002 /$ cne. 902870308

Charles, K.-A., Naudet, F., Bouali-Benazzouz, R., Landry, M., De Deurwaerdère, P., Fossat, P., et al. (2018). Alteration of nociceptive integration in the spinal cord of a rat model of Parkinson's disease. Mov. Disord. Off. J. Mov. Disord. Soc 33, 1010-1015. doi: 10.1002/mds.27377

Chaudhuri, K. R., and Schapira, A. H. V. (2009). Non-motor symptoms of Parkinson's disease: dopaminergic pathophysiology and treatment. Lancet Neurol. 8, 464-474. doi: 10.1016/S1474-4422(09)70068-7

Chotibut, T., Apple, D. M., Jefferis, R., and Salvatore, M. F. (2012). Dopamine Transporter Loss in 6-OHDA Parkinson's Model Is Unmet by Parallel Reduction in Dopamine Uptake. PloS One 7 (12), e52322. doi: 10.1371/ journal.pone.0052322

Chotibut, T., Fields, V., and Salvatore, M. F. (2014). Norepinephrine transporter inhibition with desipramine exacerbates L-DOPA-induced dyskinesia: role for 
synaptic dopamine regulation in denervated nigrostriatal terminals. Mol. Pharmacol. 86, 675-685. doi: 10.1124/mol.114.093302

Conti, M. M., Goldenberg, A. A. A., Kuberka, A., Mohamed, M., Eissa, S., Lindenbach, D., et al. (2016). Effect of tricyclic antidepressants on L-DOPAinduced dyskinesia and motor improvement in hemi-parkinsonian rats. Pharmacol. Biochem. Behav. 142, 64-71. doi: 10.1016/j.pbb.2016.01.004

Cullen, K. P., Grant, L. M., Kelm-Nelson, C. A., Brauer, A. F. L., Bickelhaupt, L. B., Russell, J. A., et al. (2018). Pink1 -/- Rats Show Early-Onset Swallowing Deficits and Correlative Brainstem Pathology. Dysphagia 33, 749-758. doi: 10.1007/s00455-018-9896-5

Cummings, J., Ritter, A., and Rothenberg, K. (2019). Advances in Management of Neuropsychiatric Syndromes in Neurodegenerative Diseases. Curr. Psychiatry Rep. 21, 79. doi: 10.1007/s11920-019-1058-4

Cummings, J. L. (1992). Depression and Parkinson's disease: a review. Am. J. Psychiatry 149, 443-454. doi: 10.1176/ajp.149.4.443

Curtis, A. L., Leiser, S. C., Snyder, K., and Valentino, R. J. (2012). Predator stress engages corticotropin-releasing factor and opioid systems to alter the operating mode of locus coeruleus norepinephrine neurons. Neuropharmacology 62, 1737-1745. doi: 10.1016/j.neuropharm.2011.11.020

Dayan, L., and Finberg, J. P. M. (2003). L-DOPA increases noradrenaline turnover in central and peripheral nervous systems. Neuropharmacology 45, 524-533. doi: 10.1016/s0028-3908(03)00190-4

De Deurwaerdère, P., Di Giovanni, G., and Millan, M. J. (2017). Expanding the repertoire of L-DOPA's actions: A comprehensive review of its functional neurochemistry. Prog. Neurobiol. 151, 57-100. doi: 10.1016/ j.pneurobio.2016.07.002

Dekundy, A., Lundblad, M., Danysz, W., and Cenci, M. A. (2007). Modulation of L-DOPA-induced abnormal involuntary movements by clinically tested compounds: further validation of the rat dyskinesia model. Behav. Brain Res. 179, 76-89. doi: 10.1016/j.bbr.2007.01.013

Del Tredici, K., and Braak, H. (2013). Dysfunction of the locus coeruleusnorepinephrine system and related circuitry in Parkinson's disease-related dementia. J. Neurol. Neurosurg. Psychiatry 84, 774-783. doi: 10.1136/jnnp2011-301817

Del Tredici, K., Rüb, U., De Vos, R. A. I., Bohl, J. R. E., and Braak, H. (2002). Where does parkinson disease pathology begin in the brain? J. Neuropathol. Exp. Neurol. 61, 413-426. doi: 10.1093/jnen/61.5.413

Delaville, C., Deurwaerdère, P. D., and Benazzouz, A. (2011). Noradrenaline and Parkinson's disease. Front. Syst. Neurosci. 5, 31. doi: 10.3389/fnsys.2011.00031

Delaville, C., Chetrit, J., Abdallah, K., Morin, S., Cardoit, L., De Deurwaerdère, P., et al. (2012a). Emerging dysfunctions consequent to combined monoaminergic depletions in Parkinsonism. Neurobiol. Dis. 45, 763-773. doi: 10.1016/ j.nbd.2011.10.023

Delaville, C., Navailles, S., and Benazzouz, A. (2012b). Effects of noradrenaline and serotonin depletions on the neuronal activity of globus pallidus and substantia nigra pars reticulata in experimental parkinsonism. Neuroscience 202, 424-433. doi: 10.1016/j.neuroscience.2011.11.024

Delfs, J. M., Zhu, Y., Druhan, J. P., and Aston-Jones, G. S. (1998). Origin of noradrenergic afferents to the shell subregion of the nucleus accumbens: anterograde and retrograde tract-tracing studies in the rat. Brain Res. 806, 127-140. doi: 10.1016/s0006-8993(98)00672-6

Devoto, P., Flore, G., Pani, L., and Gessa, G. L. (2001). Evidence for co-release of noradrenaline and dopamine from noradrenergic neurons in the cerebral cortex. Mol. Psychiatry 6, 657-664. doi: 10.1038/sj.mp.4000904

Devoto, P., Flore, G., Longu, G., Pira, L., and Gessa, G. L. (2003). Origin of extracellular dopamine from dopamine and noradrenaline neurons in the medial prefrontal and occipital cortex. Synap. N. Y. N 50, 200-205. doi: 10.1002/syn.10264

Devoto, P., Flore, G., Pira, L., Longu, G., and Gessa, G. L. (2004). Alpha2adrenoceptor mediated co-release of dopamine and noradrenaline from noradrenergic neurons in the cerebral cortex. J. Neurochem. 88, 1003-1009. doi: 10.1046/j.1471-4159.2003.02239.x

Devoto, P., Flore, G., Saba, P., Fà, M., and Gessa, G. L. (2005a). Co-release of noradrenaline and dopamine in the cerebral cortex elicited by single train and repeated train stimulation of the locus coeruleus. BMC Neurosci. 6, 31. doi: 10.1186/1471-2202-6-31

Devoto, P., Flore, G., Saba, P., Fà, M., and Gessa, G. L. (2005b). Stimulation of the locus coeruleus elicits noradrenaline and dopamine release in the medial prefrontal and parietal cortex. J. Neurochem. 92, 368-374. doi: 10.1111/ j.1471-4159.2004.02866.x

Domenici, R. A., Campos, A. C. P., Maciel, S. T., Berzuino, M. B., Hernandes, M. S., Fonoff, E. T., et al. (2019). Parkinson's disease and pain: Modulation of nociceptive circuitry in a rat model of nigrostriatal lesion. Exp. Neurol. 315, 7281. doi: 10.1016/j.expneurol.2019.02.007

Engeln, M., De Deurwaerdère, P., Li, Q., Bezard, E., and Fernagut, P.-O. (2015). Widespread Monoaminergic Dysregulation of Both Motor and Non-Motor Circuits in Parkinsonism and Dyskinesia. Cereb. Cortex 25, 2783-2792. doi: $10.1093 /$ cercor/bhu076

Eskow Jaunarajs, K. L., Dupre, K. B., Ostock, C. Y., Button, T., Deak, T., and Bishop, C. (2010). Behavioral and neurochemical effects of chronic L-DOPA treatment on nonmotor sequelae in the hemiparkinsonian rat. Behav. Pharmacol. 21, 627-637. doi: 10.1097/FBP.0b013e32833e7e80

Eskow Jaunarajs, K. L., Angoa-Perez, M., Kuhn, D. M., and Bishop, C. (2011). Potential mechanisms underlying anxiety and depression in Parkinson's disease: consequences of 1-DOPA treatment. Neurosci. Biobehav. Rev. 35, 556-564. doi: 10.1016/j.neubiorev.2010.06.007

Espay, A. J., LeWitt, P. A., and Kaufmann, H. (2014). Norepinephrine deficiency in Parkinson's disease: the case for noradrenergic enhancement. Mov. Disord. Off. J. Mov. Disord. Soc 29, 1710-1719. doi: 10.1002/mds.26048

Fallon, J. H., Koziell, D. A., and Moore, R. Y. (1978). Catecholamine innervation of the basal forebrain. II. Amygdala, suprarhinal cortex and entorhinal cortex. J. Comp. Neurol. 180, 509-532. doi: 10.1002/cne.901800308

Ferro, M. M., Bellissimo, M. I., Anselmo-Franci, J. A., Angellucci, M. E. M., Canteras, N. S., and Da Cunha, C. (2005). Comparison of bilaterally 6-OHDAand MPTP-lesioned rats as models of the early phase of Parkinson's disease: histological, neurochemical, motor and memory alterations. J. Neurosci. Methods 148, 78-87. doi: 10.1016/j.jneumeth.2005.04.005

Fitoussi, A., Dellu-Hagedorn, F., and De Deurwaerdère, P. (2013). Monoamines tissue content analysis reveals restricted and site-specific correlations in brain regions involved in cognition. Neuroscience 255, 233-245. doi: 10.1016/ j.neuroscience.2013.09.059

Fornai, F., Bassi, L., Torracca, M. T., Scalori, V., and Corsini, G. U. (1995). Norepinephrine loss exacerbates methamphetamine-induced striatal dopamine depletion in mice. Eur. J. Pharmacol. 283, 99-102. doi: 10.1016/ 0014-2999(95)00313-A

Fornai, F., Alessandrì, M. G., Torracca, M. T., Bassi, L., and Corsini, G. U. (1997). Effects of noradrenergic lesions on MPTP/MPP+ kinetics and MPTP-induced nigrostriatal dopamine depletions. J. Pharmacol. Exp. Ther. 283, 100-107.

Fox, S. H., and Brotchie, J. M. (2010). The MPTP-lesioned non-human primate models of Parkinson's disease. Past, present, and future. Prog. Brain Res. 184, 133-157. doi: 10.1016/S0079-6123(10)84007-5

Fox, S. H., Henry, B., Hill, M. P., Peggs, D., Crossman, A. R., and Brotchie, J. M. (2001). Neural mechanisms underlying peak-dose dyskinesia induced by levodopa and apomorphine are distinct: evidence from the effects of the alpha(2) adrenoceptor antagonist idazoxan. Mov. Disord. Off. J. Mov. Disord. Soc 16, 642-650. doi: $10.1002 / \mathrm{mds} .1148$

Frisina, P. G., Haroutunian, V., and Libow, L. S. (2009). The neuropathological basis for depression in Parkinson's disease. Parkinsonism Relat. Disord. 15, 144-148. doi: 10.1016/j.parkreldis.2008.04.038

Fulceri, F., Biagioni, F., Ferrucci, M., Lazzeri, G., Bartalucci, A., Galli, V., et al. (2007). Abnormal involuntary movements (AIMs) following pulsatile dopaminergic stimulation: severe deterioration and morphological correlates following the loss of locus coeruleus neurons. Brain Res. 1135, 219-229. doi: 10.1016/j.brainres.2006.12.030

Gagnon, J.-F., Postuma, R. B., and Montplaisir, J. (2006). Update on the pharmacology of REM sleep behavior disorder. Neurology 67, 742-747. doi: 10.1212/01.wnl.0000233926.47469.73

Gaspar, P., and Gray, F. (1984). Dementia in idiopathic Parkinson's disease. A neuropathological study of 32 cases. Acta Neuropathol. (Berl.) 64, 43-52. doi: $10.1007 /$ bf 00695605

Gerhard, A., Pavese, N., Hotton, G., Turkheimer, F., Es, M., Hammers, A., et al. (2006). In vivo imaging of microglial activation with [11C](R)-PK11195 PET in idiopathic Parkinson's disease. Neurobiol. Dis. 21, 404-412. doi: 10.1016/ j.nbd.2005.08.002

Gerlach, M., Halley, P., Riederer, P., and van den Buuse, M. (2013). The effect of piribedil on L-DOPA-induced dyskinesias in a rat model of Parkinson's 
disease: differential role of $\alpha(2)$ adrenergic mechanisms. J. Neural Transm. Vienna Austria 1996 120, 31-36. doi: 10.1007/s00702-012-0818-7

German, D. C., Manaye, K. F., White, C. L., Woodward, D. J., McIntire, D. D., Smith, W. K., et al. (1992). Disease-specific patterns of locus coeruleus cell loss. Ann. Neurol. 32, 667-676. doi: 10.1002/ana.410320510

Giaime, E., Tong, Y., Wagner, L. K., Yuan, Y., Huang, G., and Shen, J. (2017). AgeDependent Dopaminergic Neurodegeneration and Impairment of the Autophagy-Lysosomal Pathway in LRRK-Deficient Mice. Neuron 96, 796807.e6. doi: 10.1016/j.neuron.2017.09.036

Giasson, B. I., Duda, J. E., Quinn, S. M., Zhang, B., Trojanowski, J. Q., and Lee, V. M.-Y. (2002). Neuronal $\alpha$-Synucleinopathy with Severe Movement Disorder in Mice Expressing A53T Human $\alpha$-Synuclein. Neuron 34, 521-533. doi: 10.1016/S0896-6273(02)00682-7

Glass, C. K., Saijo, K., Winner, B., Marchetto, M. C., and Gage, F. H. (2010). Mechanisms underlying inflammation in neurodegeneration. Cell 140, 918934. doi: 10.1016/j.cell.2010.02.016

Goldstein, D. S., Holmes, C., and Sharabi, Y. (2012). Cerebrospinal fluid biomarkers of central catecholamine deficiency in Parkinson's disease and other synucleinopathies. Brain J. Neurol. 135, 1900-1913. doi: 10.1093/brain/ aws 055

Goldstein, D. S. (2006). Orthostatic hypotension as an early finding in Parkinson's disease. Clin. Auton. Res. Off. J. Clin. Auton. Res. Soc 16, 46-54. doi: 10.1007/ s10286-006-0317-8

Gomez-Mancilla, B., and Bédard, P. J. (1993). Effect of nondopaminergic drugs on L-dopa-induced dyskinesias in MPTP-treated monkeys. Clin. Neuropharmacol. 16, 418-427. doi: 10.1097/00002826-199310000-00004

Grant, L. M., Kelm-Nelson, C. A., Hilby, B. L., Blue, K. V., Paul Rajamanickam, E. S., Pultorak, J. D., et al. (2015). Evidence for early and progressive ultrasonic vocalization and oromotor deficits in a PINK1 gene knockout rat model of Parkinson's disease. J. Neurosci. Res. 93, 1713-1727. doi: 10.1002/jnr.23625

Grondin, R., Hadj Tahar, A., Doan, V. D., Ladure, P., and Bédard, P. J. (2000). Noradrenoceptor antagonism with idazoxan improves L-dopa-induced dyskinesias in MPTP monkeys. Naunyn. Schmiedebergs Arch. Pharmacol. 361, 181-186. doi: 10.1007/s002109900167

Guimarães, J., Moura, E., Silva, E., Aguiar, P., Garrett, C., and Vieira-Coelho, M. A. (2013). Locus Coeruleus Is Involved in Weight Loss in a Rat Model of Parkinson's Disease: An Effect Reversed by Deep Brain Stimulation. Brain Stimulat. 6, 845-855. doi: 10.1016/j.brs.2013.06.002

Hakusui, S., Yasuda, T., Yanagi, T., Tohyama, J., Hasegawa, Y., Koike, Y., et al. (1994). A radiological analysis of heart sympathetic functions with meta-[123I] iodobenzylguanidine in neurological patients with autonomic failure. J. Auton. Nerv. Syst. 49, 81-84. doi: 10.1016/0165-1838(94)90023-x

Halliday, G., Lees, A., and Stern, M. (2011). Milestones in Parkinson's diseaseclinical and pathologic features. Mov. Disord. Off. J. Mov. Disord. Soc 26, 10151021. doi: $10.1002 / \mathrm{mds} .23669$

Henry, B., Fox, S. H., Peggs, D., Crossman, A. R., and Brotchie, J. M. (1999). The alpha2-adrenergic receptor antagonist idazoxan reduces dyskinesia and enhances anti-parkinsonian actions of L-dopa in the MPTP-lesioned primate model of Parkinson's disease. Mov. Disord. Off. J. Mov. Disord. Soc 14, 744-753. doi: 10.1002/1531-8257(199909)14:5<744::AID-MDS1006>3.0.CO;2-7

Hirao, K., Pontone, G. M., and Smith, G. S. (2015). Molecular imaging of neuropsychiatric symptoms in Alzheimer's and Parkinson's disease. Neurosci. Biobehav. Rev. 49, 157-170. doi: 10.1016/j.neubiorev.2014.11.010

Hirschberg, S., Li, Y., Randall, A., Kremer, E. J., and Pickering, A. E. (2017). Functional dichotomy in spinal- vs prefrontal-projecting locus coeruleus modules splits descending noradrenergic analgesia from ascending aversion and anxiety in rats. eLife 6, e29808. doi: 10.7554/eLife.29808

Hurst, J. H., LeWitt, P. A., Burns, R. S., Foster, N. L., and Lovenberg, W. (1985). CSF dopamine-beta-hydroxylase activity in Parkinson's disease. Neurology 35, 565-568. doi: 10.1212/wnl.35.4.565

Iravani, M. M., Sadeghian, M., Rose, S., and Jenner, P. (2014). Loss of locus coeruleus noradrenergic neurons alters the inflammatory response to LPS in substantia nigra but does not affect nigral cell loss. J. Neural Transm. Vienna Austria 1996 121, 1493-1505. doi: 10.1007/s00702-014-1223-1

Jiang, L., Chen, S.-H., Chu, C.-H., Wang, S.-J., Oyarzabal, E., Wilson, B., et al. (2015). A novel role of microglial NADPH oxidase in mediating extra-synaptic function of norepinephrine in regulating brain immune homeostasis. Glia 63, 1057-1072. doi: 10.1002/glia.22801
Jin, X., Li, S., Bondy, B., Zhong, W., Oginsky, M. F., Wu, Y., et al. (2016). Identification of a Group of GABAergic Neurons in the Dorsomedial Area of the Locus Coeruleus. PloS One 11, e0146470. doi: 10.1371/ journal.pone. 0146470

Kadar, H., Le Douaron, G., Amar, M., Ferrié, L., Figadère, B., Touboul, D., et al. (2014). MALDI mass spectrometry imaging of 1-methyl-4-phenylpyridinium (MPP+) in mouse brain. Neurotox. Res. 25, 135-145. doi: 10.1007/s12640-0139449-5

Kamińska, K., Lenda, T., Konieczny, J., Czarnecka, A., and Lorenc-Koci, E. (2017). Depressive-like neurochemical and behavioral markers of Parkinson's disease after 6-OHDA administered unilaterally to the rat medial forebrain bundle. Pharmacol. Rep. PR 69, 985-994. doi: 10.1016/j.pharep.2017.05.016

Kempadoo, K. A., Mosharov, E. V., Choi, S. J., Sulzer, D., and Kandel, E. R. (2016). Dopamine release from the locus coeruleus to the dorsal hippocampus promotes spatial learning and memory. Proc. Natl. Acad. Sci. U. S. A. 113, 14835-14840. doi: 10.1073/pnas.1616515114

Kilbourn, M. R., Sherman, P., and Abbott, L. C. (1998). Reduced MPTP neurotoxicity in striatum of the mutant mouse tottering. Synap. N. Y. N30, 205-210. doi: 10.1002/ (SICI) 1098-2396(199810)30:2<205::AID-SYN10>3.0.CO;2-0

Kim, M.-A., Lee, H. S., Lee, B. Y., and Waterhouse, B. D. (2004). Reciprocal connections between subdivisions of the dorsal raphe and the nuclear core of the locus coeruleus in the rat. Brain Res. 1026, 56-67. doi: 10.1016/ j.brainres.2004.08.022

Kim, S., Kwon, S.-H., Kam, T.-I., Panicker, N., Karuppagounder, S. S., Lee, S., et al. (2019). Transneuronal Propagation of Pathologic $\alpha$-Synuclein from the Gut to the Brain Models Parkinson's Disease. Neuron 103, 627-641.e7. doi: 10.1016/ j.neuron.2019.05.035

Kish, S. J., Shannak, K. S., Rajput, A. H., Gilbert, J. J., and Hornykiewicz, O. (1984). Cerebellar norepinephrine in patients with Parkinson's disease and control subjects. Arch. Neurol. 41, 612-614. doi: 10.1001/archneur.1984.04210080020007

Kreiner, G., Rafa-Zabłocka, K., Barut, J., Chmielarz, P., Kot, M., Bagińska, M., et al. (2019). Stimulation of noradrenergic transmission by reboxetine is beneficial for a mouse model of progressive parkinsonism. Sci. Rep. 9, 5262. doi: 10.1038/ s41598-019-41756-3

Leclair-Visonneau, L., Magy, L., Volteau, C., Clairembault, T., Le Dily, S., Préterre, C., et al. (2018). Heterogeneous pattern of autonomic dysfunction in Parkinson's disease. J. Neurol. 265, 933-941. doi: 10.1007/s00415-018-8789-8

Li, L., Feng, X., Zhou, Z., Zhang, H., Shi, Q., Lei, Z., et al. (2018). Stress Accelerates Defensive Responses to Looming in Mice and Involves a Locus oeruleusSuperior Colliculus Projection. Curr. Biol. CB 28, 859-871.e5. doi: 10.1016/ j.cub.2018.02.005

Li, Y., Jiao, Q., Du, X., Bi, M., Han, S., Jiao, L., et al. (2018). Investigation of Behavioral Dysfunctions Induced by Monoamine Depletions in a Mouse Model of Parkinson's Disease. Front. Cell. Neurosci. 12, 241. doi: 10.3389/ fncel.2018.00241

Li, Y., Wang, C., Wang, J., Zhou, Y., Ye, F., Zhang, Y., et al. (2019). Mild cognitive impairment in de novo Parkinson's disease: A neuromelanin MRI study in locus coeruleus. Mov. Disord. Off. J. Mov. Disord. Soc 34, 884-892. doi: 10.1002/ mds. 27682

Liu, B., Teschemacher, A. G., and Kasparov, S. (2017). Astroglia as a cellular target for neuroprotection and treatment of neuro-psychiatric disorders. Glia 65, 1205-1226. doi: 10.1002/glia.23136

Llorca-Torralba, M., Suárez-Pereira, I., Bravo, L., Camarena-Delgado, C., GarciaPartida, J. A., Mico, J. A., et al. (2019). Chemogenetic Silencing of the Locus Coeruleus-Basolateral Amygdala Pathway Abolishes Pain-Induced Anxiety and Enhanced Aversive Learning in Rats. Biol. Psychiatry 85, 1021-1035. doi: 10.1016/j.biopsych.2019.02.018

Loughlin, S. E., Foote, S. L., and Bloom, F. E. (1986). Efferent projections of nucleus locus coeruleus: topographic organization of cells of origin demonstrated by three-dimensional reconstruction. Neuroscience 18, 291306. doi: 10.1016/0306-4522(86)90155-7

Lu, Y., Simpson, K. L., Weaver, K. J., and Lin, R. C. S. (2012). Differential distribution patterns from medial prefrontal cortex and dorsal raphe to the locus coeruleus in rats. Anat. Rec. Hoboken NJ 2007 295, 1192-1201. doi: $10.1002 / a r .22505$

Luchtman, D. W., Shao, D., and Song, C. (2009). Behavior, neurotransmitters and inflammation in three regimens of the MPTP mouse model of Parkinson's disease. Physiol. Behav. 98, 130-138. doi: 10.1016/j.physbeh.2009.04.021 
Marien, M., Briley, M., and Colpaert, F. (1993). Noradrenaline depletion exacerbates MPTP-induced striatal dopamine loss in mice. Eur. J. Pharmacol. 236, 487-489. doi: 10.1016/0014-2999(93)90489-5

Martin-Bastida, A., Pietracupa, S., and Piccini, P. (2017). Neuromelanin in parkinsonian disorders: an update. Int. J. Neurosci. 127, 1116-1123. doi: 10.1080/00207454.2017.1325883

Martinez-Martin, P., Chaudhuri, K. R., Rojo-Abuin, J. M., Rodriguez-Blazquez, C., Alvarez-Sanchez, M., Arakaki, T., et al. (2015). Assessing the non-motor symptoms of Parkinson's disease: MDS-UPDRS and NMS Scale. Eur. J. Neurol. 22, 37-43. doi: 10.1111/ene.12165

Masilamoni, G. J., Groover, O., and Smith, Y. (2017). Reduced noradrenergic innervation of ventral midbrain dopaminergic cell groups and the subthalamic nucleus in MPTP-treated parkinsonian monkeys. Neurobiol. Dis. 100, 9-18. doi: 10.1016/j.nbd.2016.12.025

Mason, S. T., and Fibiger, H. C. (1979). Regional topography within noradrenergic locus coeruleus as revealed by retrograde transport of horseradish peroxidase. J. Comp. Neurol. 187, 703-724. doi: 10.1002/cne.901870405

Mavridis, M., Degryse, A. D., Lategan, A. J., Marien, M. R., and Colpaert, F. C. (1991). Effects of locus coeruleus lesions on parkinsonian signs, striatal dopamine and substantia nigra cell loss after 1-methyl-4-phenyl-1,2,3,6tetrahydropyridine in monkeys: a possible role for the locus coeruleus in the progression of Parkinson's disease. Neuroscience 41, 507-523. doi: 10.1016/ 0306-4522(91)90345-o

McCall, J. G., Al-Hasani, R., Siuda, E. R., Hong, D. Y., Norris, A. J., Ford, C. P., et al. (2015). CRH Engagement of the Locus Coeruleus Noradrenergic System Mediates Stress-Induced Anxiety. Neuron 87, 605-620. doi: 10.1016/ j.neuron.2015.07.002

McCall, J. G., Siuda, E. R., Bhatti, D. L., Lawson, L. A., McElligott, Z. A., Stuber, G. D., et al. (2017). Locus coeruleus to basolateral amygdala noradrenergic projections promote anxiety-like behavior. eLife 6, e18247. doi: 10.7554/ eLife. 18247

McMillan, P. J., White, S. S., Franklin, A., Greenup, J. L., Leverenz, J. B., Raskind, M. A., et al. (2011). Differential response of the central noradrenergic nervous system to the loss of locus coeruleus neurons in Parkinson's disease and Alzheimer's disease. Brain Res. 1373, 240-252. doi: 10.1016/ j.brainres.2010.12.015

McNamee, E. N., Griffin, E. W., Ryan, K. M., Ryan, K. J., Heffernan, S., Harkin, A., et al. (2010a). Noradrenaline acting at beta-adrenoceptors induces expression of IL-1beta and its negative regulators IL-1ra and IL-1RII, and drives an overall anti-inflammatory phenotype in rat cortex. Neuropharmacology 59, 37-48. doi: 10.1016/j.neuropharm.2010.03.014

McNamee, E. N., Ryan, K. M., Kilroy, D., and Connor, T. J. (2010b). Noradrenaline induces IL-1ra and IL-1 type II receptor expression in primary glial cells and protects against IL-1beta-induced neurotoxicity. Eur. J. Pharmacol. 626, 219-228. doi: 10.1016/j.ejphar.2009.09.054

Mejías-Aponte, C. A., Drouin, C., and Aston-Jones, G. (2009). Adrenergic and Noradrenergic Innervation of the Midbrain Ventral Tegmental Area and Retrorubral Field: Prominent Inputs from Medullary Homeostatic Centers. J. Neurosci. 29, 3613-3626. doi: 10.1523/JNEUROSCI.4632-08.2009

Micieli, G., Tosi, P., Marcheselli, S., and Cavallini, A. (2003). Autonomic dysfunction in Parkinson's disease. Neurol. Sci. Off. J. Ital. Neurol. Soc Ital. Soc Clin. Neurophysiol. 24 (Suppl 1), S32-S34. doi: 10.1007/s100720300035

Miguelez, C., Aristieta, A., Cenci, M. A., and Ugedo, L. (2011a). The locus coeruleus is directly implicated in L-DOPA-induced dyskinesia in parkinsonian rats: an electrophysiological and behavioural study. PloS One 6, e24679. doi: 10.1371/journal.pone.0024679

Miguelez, C., Grandoso, L., and Ugedo, L. (2011b). Locus coeruleus and dorsal raphe neuron activity and response to acute antidepressant administration in a rat model of Parkinson's disease. Int. J. Neuropsychopharmacol. 14, 187-200. doi: $10.1017 /$ S146114571000043X

Miguelez, C., Berrocoso, E., Mico, J. A., and Ugedo, L. (2013). L-DOPA modifies the antidepressant-like effects of reboxetine and fluoxetine in rats. Neuropharmacology 67, 349-358. doi: 10.1016/j.neuropharm.2012.11.016

Miguelez, C., Benazzouz, A., Ugedo, L., and De Deurwaerdère, P. (2017). Impairment of Serotonergic Transmission by the Antiparkinsonian Drug LDOPA: Mechanisms and Clinical Implications. Front. Cell. Neurosci. 11, 274. doi: $10.3389 /$ fncel.2017.00274
Mittal, S., Bjørnevik, K., Im, D. S., Flierl, A., Dong, X., Locascio, J. J., et al. (2017). $\beta 2$-Adrenoreceptor is a regulator of the $\alpha$-synuclein gene driving risk of Parkinson's disease. Science 357, 891-898. doi: 10.1126/science.aaf3934

Monaca, C., Laloux, C., Jacquesson, J.-M., Gelé, P., Maréchal, X., Bordet, R., et al. (2004). Vigilance states in a parkinsonian model, the MPTP mouse. Eur. J. Neurosci. 20, 2474-2478. doi: 10.1111/j.1460-9568.2004.03694.x

Morón, J. A., Brockington, A., Wise, R. A., Rocha, B. A., and Hope, B. T. (2002). Dopamine uptake through the norepinephrine transporter in brain regions with low levels of the dopamine transporter: evidence from knock-out mouse lines. J. Neurosci. Off. J. Soc Neurosci. 22, 389-395. doi: 10.1523/ JNEUROSCI.22-02-00389.2002

Mori, K., Ozaki, E., Zhang, B., Yang, L., Yokoyama, A., Takeda, I., et al. (2002). Effects of norepinephrine on rat cultured microglial cells that express alpha1, alpha2, beta1 and beta2 adrenergic receptors. Neuropharmacology 43, 10261034. doi: 10.1016/s0028-3908(02)00211-3

Navailles, S., and De Deurwaerdère, P. (2012). Imbalanced Dopaminergic Transmission Mediated by Serotonergic Neurons in L-DOPA-Induced Dyskinesia. Park. Dis. 2012, 323686. doi: 10.1155/2012/323686

Navailles, S., Bioulac, B., Gross, C., and De Deurwaerdère, P. (2010). Serotonergic neurons mediate ectopic release of dopamine induced by L-DOPA in a rat model of Parkinson's disease. Neurobiol. Dis. 38, 136-143. doi: 10.1016/ j.nbd.2010.01.012

Navailles, S., Milan, L., Khalki, H., Di Giovanni, G., Lagière, M., and De Deurwaerdère, P. (2014). Noradrenergic terminals regulate L-DOPA-derived dopamine extracellular levels in a region-dependent manner in Parkinsonian rats. CNS Neurosci. Ther. 20, 671-678. doi: 10.1111/cns.12275

Nayyar, T., Bubser, M., Ferguson, M. C., Neely, M. D., Goodwin, J. S., Montine, T. J., et al. (2009). Cortical serotonin and norepinephrine denervation in parkinsonism: preferential loss of the beaded serotonin innervation. Eur. J. Neurosci. 30, 207-216. doi: 10.1111/j.1460-9568.2009.06806.x

O'Connor, D. T., Cervenka, J. H., Stone, R. A., Levine, G. L., Parmer, R. J., FrancoBourland, R. E., et al. (1994). Dopamine beta-hydroxylase immunoreactivity in human cerebrospinal fluid: properties, relationship to central noradrenergic neuronal activity and variation in Parkinson's disease and congenital dopamine beta-hydroxylase deficiency. Clin. Sci. Lond. Engl. 1979 86, $149-$ 158. doi: $10.1042 / \mathrm{cs} 0860149$

Olanow, C. W., Stern, M. B., and Sethi, K. (2009). The scientific and clinical basis for the treatment of Parkinson disease, (2009). Neurology 72, S1-136. doi: 10.1212/WNL.0b013e3181a1d44c

Ostock, C. Y., Lindenbach, D., Goldenberg, A. A., Kampton, E., and Bishop, C. (2014). Effects of noradrenergic denervation by anti-DBH-saporin on behavioral responsivity to L-DOPA in the hemi-parkinsonian rat. Behav. Brain Res. 270, 75-85. doi: 10.1016/j.bbr.2014.05.009

Ostock, C. Y., Hallmark, J., Palumbo, N., Bhide, N., Conti, M., George, J. A., et al. (2015). Modulation of L-DOPA's antiparkinsonian and dyskinetic effects by $\alpha 2$-noradrenergic receptors within the locus coeruleus. Neuropharmacology 95 , 215-225. doi: 10.1016/j.neuropharm.2015.03.008

Ostock, C. Y., Bhide, N., Goldenberg, A. A., George, J. A., and Bishop, C. (2018). Striatal norepinephrine efflux in 1-DOPA-induced dyskinesia. Neurochem. Int. 114, 85-98. doi: 10.1016/j.neuint.2018.01.010

Ouchi, Y., Yoshikawa, E., Sekine, Y., Futatsubashi, M., Kanno, T., Ogusu, T., et al. (2005). Microglial activation and dopamine terminal loss in early Parkinson's disease. Ann. Neurol. 57, 168-175. doi: 10.1002/ana.20338

Pérez, V., Sosti, V., Rubio, A., Barbanoj, M., Rodríguez-Alvarez, J., and Kulisevsky, J. (2007). Modulation of the motor response to dopaminergic drugs in a parkinsonian model of combined dopaminergic and noradrenergic degeneration. Eur. J. Pharmacol. 576, 83-90. doi: 10.1016/j.ejphar.2007.08.024

Pérez, V., Marin, C., Rubio, A., Aguilar, E., Barbanoj, M., and Kulisevsky, J. (2009). Effect of the additional noradrenergic neurodegeneration to 6-OHDA-lesioned rats in levodopa-induced dyskinesias and in cognitive disturbances. J. Neural Transm. Vienna Austria 1996 116, 1257-1266. doi: 10.1007/s00702-009-0291-0

Park, A., and Stacy, M. (2009). Non-motor symptoms in Parkinson's disease. J. Neurol. 256 Suppl 3, 293-298. doi: 10.1007/s00415-009-5240-1

Pascucci, T., Giacovazzo, G., Andolina, D., Conversi, D., Cruciani, F., Cabib, S., et al. (2012). In vivo catecholaminergic metabolism in the medial prefrontal cortex of ENU2 mice: an investigation of the cortical dopamine deficit in phenylketonuria. J. Inherit. Metab. Dis. 35, 1001-1009. doi: 10.1007/s10545-012-9473-2 
Patt, S., and Gerhard, L. (1993). A Golgi study of human locus coeruleus in normal brains and in Parkinson's disease. Neuropathol. Appl. Neurobiol. 19, 519-523. doi: 10.1111/j.1365-2990.1993.tb00480.x

Pavese, N., Rivero-Bosch, M., Lewis, S. J., Whone, A. L., and Brooks, D. J. (2011). Progression of monoaminergic dysfunction in Parkinson's disease: a longitudinal 18F-dopa PET study. NeuroImage 56, 1463-1468. doi: 10.1016/ j.neuroimage.2011.03.012

Pifl, Ch., Schingnitz, G., and Hornykiewicz, O. (1991). Effect of 1-methyl-4phenyl-1,2,3,6-tetrahydropyridine on the regional distribution of brain monoamines in the rhesus monkey. Neuroscience 44, 591-605. doi: 10.1016/ 0306-4522(91)90080-8

Pifl, C., Kish, S. J., and Hornykiewicz, O. (2012). Thalamic noradrenaline in Parkinson's disease: deficits suggest role in motor and non-motor symptoms. Mov. Disord. Off. J.Mov. Disord. Soc 27, 1618-1624. doi: 10.1002/mds.25109

Qian, L., Wu, H., Chen, S.-H., Zhang, D., Ali, S. F., Peterson, L., et al. (2011). $\beta 2-$ adrenergic receptor activation prevents rodent dopaminergic neurotoxicity by inhibiting microglia via a novel signaling pathway. J. Immunol. Baltim. Md 1950 186, 4443-4454. doi: 10.4049/jimmunol.1002449

Remy, P., Doder, M., Lees, A., Turjanski, N., and Brooks, D. (2005). Depression in Parkinson's disease: loss of dopamine and noradrenaline innervation in the limbic system. Brain J. Neurol. 128, 1314-1322. doi: 10.1093/brain/awh445

Rey, N. L., Petit, G. H., Bousset, L., Melki, R., and Brundin, P. (2013). Transfer of human $\alpha$-synuclein from the olfactory bulb to interconnected brain regions in mice. ActaNeuropathol. (Berl.) 126, 555-573. doi: 10.1007/s00401-013-1160-3

Rommelfanger, K. S., and Weinshenker, D. (2007). Norepinephrine: The redheaded stepchild of Parkinson's disease. Biochem. Pharmacol. 74, 177190. doi: 10.1016/j.bcp.2007.01.036

Rommelfanger, K. S., Weinshenker, D., and Miller, G. W. (2004). Reduced MPTP toxicity in noradrenaline transporter knockout mice. J. Neurochem. 91, 11161124. doi: 10.1111/j.1471-4159.2004.02785.x

Rusconi, R., Ulusoy, A., Aboutalebi, H., and Di Monte, D. A. (2018). Long-lasting pathological consequences of overexpression-induced $\alpha$-synuclein spreading in the rat brain. Aging Cell 17 (2). doi: 10.1111/acel.12727

Ryan, M., Eatmon, C. V., and Slevin, J. T. (2019). Drug treatment strategies for depression in Parkinson disease. Expert Opin.Pharmacother. 20, 1351-1363. doi: 10.1080/14656566.2019.1612877

Santiago, R. M., Barbieiro, J., Lima, M. M. S., Dombrowski, P. A., Andreatini, R, and Vital, M. A. B. F. (2010). Depressive-like behaviors alterations induced by intranigral MPTP, 6-OHDA, LPS and rotenone models of Parkinson's disease are predominantly associated with serotonin and dopamine. Prog. Neuropsychopharmacol. Biol. Psychiatry 34, 1104-1114. doi: 10.1016/j.pnpbp.2010.06.004

Sara, S. J., and Bouret, S. (2012). Orienting and reorienting: the locus coeruleus mediates cognition through arousal. Neuron 76, 130-141. doi: 10.1016/ j.neuron.2012.09.011

Sasaki, M., Shibata, E., Tohyama, K., Takahashi, J., Otsuka, K., Tsuchiya, K., et al. (2006). Neuromelanin magnetic resonance imaging of locus ceruleus and substantia nigra in Parkinson's disease. Neuroreport 17, 1215-1218. doi: 10.1097/01.wnr.0000227984.84927.a7

Savola, J.-M., Hill, M., Engstrom, M., Merivuori, H., Wurster, S., McGuire, S. G., et al. (2003). Fipamezole (JP-1730) is a potent alpha2 adrenergic receptor antagonist that reduces levodopa-induced dyskinesia in the MPTP-lesioned primate model of Parkinson's disease. Mov. Disord. Off. J.Mov. Disord. Soc 18, 872-883. doi: $10.1002 / \mathrm{mds} .10464$

Schapira, A. H. V., Chaudhuri, K. R., and Jenner, P. (2017). Non-motor features of Parkinson disease. Nat. Rev. Neurosci. 18, 435-450. doi: 10.1038/nrn.2017.62

Schwarz, L. A., and Luo, L. (2015). Organization of the locus coeruleusnorepinephrine system. Curr. Biol. CB 25, R1051-R1056. doi: 10.1016/ j.cub.2015.09.039

Schwarz, L. A., Miyamichi, K., Gao, X. J., Beier, K. T., Weissbourd, B., DeLoach, K. E., et al. (2015). Viral-genetic tracing of the input-output organization of a central noradrenaline circuit. Nature 524, 88-92. doi: 10.1038/nature14600

Schwarz, S. T., Xing, Y., Tomar, P., Bajaj, N., and Auer, D. P. (2017). In Vivo Assessment of Brainstem Depigmentation in Parkinson Disease: Potential as a Severity Marker for Multicenter Studies. Radiology 283, 789-798. doi: 10.1148/ radiol.2016160662

Senard, J. M., Valet, P., Durrieu, G., Berlan, M., Tran, M. A., Montastruc, J. L., et al. (1990). Adrenergic supersensitivity in parkinsonians with orthostatic hypotension. Eur. J. Clin. Invest. 20, 613-619. doi: 10.1111/j.1365-2362.1990.tb01909.x
Shannak, K., Rajput, A., Rozdilsky, B., Kish, S., Gilbert, J., and Hornykiewicz, O. (1994). Noradrenaline, dopamine and serotonin levels and metabolism in the human hypothalamus: observations in Parkinson's disease and normal subjects. Brain Res. 639, 33-41. doi: 10.1016/0006-8993(94)91761-2

Sharabi, Y., Imrich, R., Holmes, C., Pechnik, S., and Goldstein, D. S. (2008). Generalized and neurotransmitter-selective noradrenergic denervation in Parkinson's disease with orthostatic hypotension. Mov. Disord. Off. J. Mov. Disord. Soc 23, 1725-1732. doi: 10.1002/mds.22226

Shiba, M., Bower, J. H., Maraganore, D. M., McDonnell, S. K., Peterson, B. J., Ahlskog, J. E., et al. (2000). Anxiety disorders and depressive disorders preceding Parkinson's disease: a case-control study. Mov. Disord. Off. J. Mov. Disord. Soc 15, 669-677. doi: 10.1002/1531-8257(200007)15:4<669::AIDMDS1011>3.0.CO;2-5

Shin, E., Rogers, J. T., Devoto, P., Björklund, A., and Carta, M. (2014). Noradrenaline neuron degeneration contributes to motor impairments and development of L-DOPA-induced dyskinesia in a rat model of Parkinson's disease. Exp. Neurol. 257, 25-38. doi: 10.1016/j.expneurol.2014.04.011

Shipley, M. T., Halloran, F. J., and de la Torre, J. (1985). Surprisingly rich projection from locus coeruleus to the olfactory bulb in the rat. Brain Res. 329, 294-299. doi: 10.1016/0006-8993(85)90537-2

Slaets, S., Van Acker, F., Versijpt, J., Hauth, L., Goeman, J., Martin, J.-J., et al. (2015). Diagnostic value of MIBG cardiac scintigraphy for differential dementia diagnosis. Int. J. Geriatr. Psychiatry 30, 864-869. doi: 10.1002/gps.4229

Smith, C. C., and Greene, R. W. (2012). CNS dopamine transmission mediated by noradrenergic innervation. J. Neurosci. Off. J. Soc Neurosci. 32, 6072-6080. doi: 10.1523/JNEUROSCI.6486-11.2012

Sommerauer, M., Fedorova, T. D., Hansen, A. K., Knudsen, K., Otto, M., Jeppesen, J., et al. (2018a). Evaluation of the noradrenergic system in Parkinson's disease: an 11C-MeNER PET and neuromelanin MRI study. Brain J. Neurol. 141, 496504. doi: 10.1093/brain/awx348

Sommerauer, M., Hansen, A. K., Parbo, P., Fedorova, T. D., Knudsen, K., Frederiksen, Y., et al. (2018b). Decreased noradrenaline transporter density in the motor cortex of Parkinson's disease patients. Mov. Disord. Off. J. Mov. Disord. Soc 33, 1006-1010. doi: 10.1002/mds.27411

Song, S., Wang, Q., Jiang, L., Oyarzabal, E., Riddick, N. V., Wilson, B., et al. (2019). Noradrenergic dysfunction accelerates LPS-elicited inflammation-related ascending sequential neurodegeneration and deficits in non-motor/motor functions. Brain. Behav. Immun. 81, 374-387. doi: 10.1016/j.bbi.2019.06.034

Sotiriou, E., Vassilatis, D. K., Vila, M., and Stefanis, L. (2010). Selective noradrenergic vulnerability in alpha-synuclein transgenic mice. Neurobiol, Aging 31, 2103-2114. doi: 10.1016/j.neurobiolaging.2008.11.010

Srinivasan, J., and Schmidt, W. J. (2003). Potentiation of parkinsonian symptoms by depletion of locus coeruleus noradrenaline in 6-hydroxydopamine-induced partial degeneration of substantia nigra in rats. Eur. J. Neurosci. 17, 2586-2592. doi: $10.1046 / j .1460-9568.2003 .02684 . x$

Srinivasan, J., and Schmidt, W. J. (2004). Behavioral and neurochemical effects of noradrenergic depletions with $\mathrm{N}$-(2-chloroethyl)-N-ethyl-2-bromobenzylamine in 6-hydroxydopamine-induced rat model of Parkinson's disease. Behav. Brain Res. 151, 191-199. doi: 10.1016/j.bbr.2003.08.016

Stacy, M. (2002). Sleep disorders in Parkinson's disease: epidemiology and management. Drugs Aging 19, 733-739. doi: 10.2165/00002512-20021910000002

Szot, P., Franklin, A., Miguelez, C., Wang, Y., Vidaurrazaga, I., Ugedo, L., et al. (2016). Depressive-like behavior observed with a minimal loss of locus coeruleus (LC) neurons following administration of 6-hydroxydopamine is associated with electrophysiological changes and reversed with precursors of norepinephrine. Neuropharmacology 101, 76-86. doi: 10.1016/j.neuropharm.2015.09.003

Tadaiesky, M. T., Dombrowski, P. A., Figueiredo, C. P., Cargnin-Ferreira, E., Da Cunha, C., and Takahashi, R. N. (2008). Emotional, cognitive and neurochemical alterations in a premotor stage model of Parkinson's disease. Neuroscience 156, 830-840. doi: 10.1016/j.neuroscience.2008.08.035

Takatsu, H., Nishida, H., Matsuo, H., Watanabe, S., Nagashima, K., Wada, H., et al. (2000). Cardiac sympathetic denervation from the early stage of Parkinson's disease: clinical and experimental studies with radiolabeled MIBG. J. Nucl. Med. Off. Publ. Soc Nucl. Med. 41, 71-77.

Takeuchi, T., Duszkiewicz, A. J., Sonneborn, A., Spooner, P. A., Yamasaki, M., Watanabe, M., et al. (2016). Locus coeruleus and dopaminergic consolidation of everyday memory. Nature 537, 357-362. doi: 10.1038/nature19325 
Tanaka, H., Kannari, K., Maeda, T., Tomiyama, M., Suda, T., and Matsunaga, M. (1999). Role of serotonergic neurons in L-DOPA-derived extracellular dopamine in the striatum of 6-OHDA-lesioned rats. Neuroreport 10, 631634. doi: 10.1097/00001756-199902250-00034

Tanaka, K. F., Kashima, H., Suzuki, H., Ono, K., and Sawada, M. (2002). Existence of functional beta1- and beta2-adrenergic receptors on microglia. J. Neurosci. Res. 70, 232-237. doi: 10.1002/jnr.10399

Terada, T., Yokokura, M., Yoshikawa, E., Futatsubashi, M., Kono, S., Konishi, T., et al. (2016). Extrastriatal spreading of microglial activation in Parkinson's disease: a positron emission tomography study. Ann. Nucl. Med. 30, 579-587. doi: 10.1007/s12149-016-1099-2

Titova, N., Schapira, A. H. V., Chaudhuri, K. R., Qamar, M. A., Katunina, E., and Jenner, P. (2017). Nonmotor Symptoms in Experimental Models of Parkinson's Disease. Int. Rev. Neurobiol. 133, 63-89. doi: 10.1016/bs.irn.2017.05.018

Tsutsumi, R., Hori, Y., Seki, T., Kurauchi, Y., Sato, M., Oshima, M., et al. (2019). Involvement of exosomes in dopaminergic neurodegeneration by microglial activation in midbrain slice cultures. Biochem. Biophys. Res. Commun. 511, 427-433. doi: 10.1016/j.bbrc.2019.02.076

Uchiyama, M., Isse, K., Tanaka, K., Yokota, N., Hamamoto, M., Aida, S., et al. (1995). Incidental Lewy body disease in a patient with REM sleep behavior disorder. Neurology 45, 709-712. doi: 10.1212/wnl.45.4.709

Ulusoy, A., Rusconi, R., Pérez-Revuelta, B. I., Musgrove, R. E., Helwig, M., Winzen-Reichert, B., et al. (2013). Caudo-rostral brain spreading of $\alpha$ synuclein through vagal connections. EMBO Mol. Med. 5, 1119-1127. doi: $10.1002 / \mathrm{emmm} .201302475$

Ulusoy, A., Phillips, R. J., Helwig, M., Klinkenberg, M., Powley, T. L., and Di Monte, D. A. (2017). Brain-to-stomach transfer of $\alpha$-synuclein via vagal preganglionic projections. Acta Neuropathol. (Berl.) 133, 381-393. doi: 10.1007/s00401-016-1661-y

Vanle, B., Olcott, W., Jimenez, J., Bashmi, L., Danovitch, I., and IsHak, W. W. (2018). NMDA antagonists for treating the non-motor symptoms in Parkinson's disease. Transl. Psychiatry 8, 117. doi: 10.1038/s41398-018-0162-2

Vazey, E. M., and Aston-Jones, G. (2012). The emerging role of norepinephrine in cognitive dysfunctions of Parkinson's disease. Front. Behav. Neurosci. 6, 48. doi: 10.3389/fnbeh.2012.00048

Vieira, J. C. F., Bassani, T. B., Santiago, R. M., de O. Guaita, G., Zanoveli, J. M., da Cunha, C., et al. (2019). Anxiety-like behavior induced by 6-OHDA animal model of Parkinson's disease may be related to a dysregulation of neurotransmitter systems in brain areas related to anxiety. Behav. Brain Res. 371, 111981. doi: 10.1016/j.bbr.2019.111981

Vila, M. (2019). Neuromelanin, aging, and neuronal vulnerability in Parkinson's disease. Mov. Disord. 34 (10), 1440-1451. doi: 10.1002/mds.27776

Vo, Q., Gilmour, T. P., Venkiteswaran, K., Fang, J., and Subramanian, T. (2014). Polysomnographic Features of Sleep Disturbances and REM Sleep Behavior Disorder in the Unilateral 6-OHDA Lesioned Hemiparkinsonian Rat. Park. Dis. 2014, 852965. doi: 10.1155/2014/852965

Von Coelln, R., Thomas, B., Savitt, J. M., Lim, K. L., Sasaki, M., Hess, E. J., et al. (2004). Loss of locus coeruleus neurons and reduced startle in parkin null mice. Proc. Natl. Acad. Sci. U. S. A. 101, 10744-10749. doi: 10.1073/pnas.0401297101

Wakabayashi, K., and Takahashi, H. (1997). Neuropathology of autonomic nervous system in Parkinson's disease. Eur. Neurol. 38 Suppl 2, 2-7. doi: $10.1159 / 000113469$
Wang, T., Zhang, Q.-J., Liu, J., Wu, Z.-H., and Wang, S. (2009). Firing activity of locus coeruleus noradrenergic neurons increases in a rodent model of Parkinsonism. Neurosci. Bull. 25, 15-20. doi: 10.1007/s12264-009-1023-Z

Wang, Y., Zhang, Q. J., Liu, J., Ali, U., Gui, Z. H., Hui, Y. P., et al. (2010). Noradrenergic lesion of the locus coeruleus increases apomorphine-induced circling behavior and the firing activity of substantia nigra pars reticulata neurons in a rat model of Parkinson's disease. Brain Res. 1310, 189-199. doi: 10.1016/j.brainres.2009.10.070

Wang, Y., Wang, H. S., Wang, T., Huang, C., and Liu, J. (2014). L-DOPA-induced dyskinesia in a rat model of Parkinson's disease is associated with the fluctuational release of norepinephrine in the sensorimotor striatum. $J$. Neurosci. Res. 92, 1733-1745. doi: 10.1002/jnr.23439

Wang, J., Li, Y., Huang, Z., Wan, W., Zhang, Y., Wang, C., et al. (2018). Neuromelanin-sensitive magnetic resonance imaging features of the substantia nigra and locus coeruleus in de novo Parkinson's disease and its phenotypes. Eur. J. Neurol. 25, 949-e73. doi: 10.1111/ene.13628

Westlund, K. N., Bowker, R. M., Ziegler, M. G., and Coulter, J. D. (1983). Noradrenergic projections to the spinal cord of the rat. Brain Res. 263, 1531. doi: 10.1016/0006-8993(83)91196-4

Yamasaki, M., and Takeuchi, T. (2017). Locus Coeruleus and DopamineDependent Memory Consolidation. Neural Plast. 2017, 8602690. doi: 10.1155/2017/8602690

Yao, N., Wu, Y., Zhou, Y., Ju, L., Liu, Y., Ju, R., et al. (2015). Lesion of the locus coeruleus aggravates dopaminergic neuron degeneration by modulating microglial function in mouse models of Parkinson's disease. Brain Res. 1625, 255-274. doi: 10.1016/j.brainres.2015.08.032

Yssel, J. D., O'Neill, E., Nolan, Y. M., Connor, T. J., and Harkin, A. (2018). Treatment with the noradrenaline re-uptake inhibitor atomoxetine alone and in combination with the $\alpha 2$-adrenoceptor antagonist idazoxan attenuates loss of dopamine and associated motor deficits in the LPS inflammatory rat model of Parkinson's disease. Brain. Behav. Immun. 69, 456-469. doi: 10.1016/ j.bbi.2018.01.004

Zarow, C., Lyness, S. A., Mortimer, J. A., and Chui, H. C. (2003). Neuronal loss is greater in the locus coeruleus than nucleus basalis and substantia nigra in Alzheimer and Parkinson diseases. Arch. Neurol. 60, 337-341. doi: 10.1001/ archneur.60.3.337

Zweig, R. M., Cardillo, J. E., Cohen, M., Giere, S., and Hedreen, J. C. (1993). The locus ceruleus and dementia in Parkinson's disease. Neurology 43, 986-991. doi: 10.1212/wnl.43.5.986

Conflict of Interest: The authors declare that the research was conducted in the absence of any commercial or financial relationships that could be construed as a potential conflict of interest.

Copyright (c) 2020 Paredes-Rodriguez, Vegas-Suarez, Morera-Herreras, De Deurwaerdere and Miguelez. This is an open-access article distributed under the terms of the Creative Commons Attribution License (CC BY). The use, distribution or reproduction in other forums is permitted, provided the original author(s) and the copyright owner(s) are credited and that the original publication in this journal is cited, in accordance with accepted academic practice. No use, distribution or reproduction is permitted which does not comply with these terms. 